\title{
Evaluation of Antitumor Efficacy of Chitosan-Tamarind Gum Polysaccharide Polyelectrolyte Complex Stabilized Nanoparticles of Simvastatin
}

This article was published in the following Dove Press journal:

International Journal of Nanomedicine

\begin{abstract}
Rishabha Malviya ${ }^{1, *}$ Shakshi Raj ${ }^{1}, *$ Shivkanya Fuloria ${ }^{2} *$

Vetriselvan Subramaniyan ${ }^{3, *}$ Kathiresan Sathasivam ${ }^{4}$ Usha Kumari ${ }^{5}$

Dhanalekshmi Unnikrishnan

Meenakshi ${ }^{6}$ Omji Porwal ${ }^{7}$

Darnal Hari Kumar ${ }^{8}$ Amit Singh

Srikumar Chakravarthi (iD) 9

Neeraj Kumar Fuloria ${ }^{2, *}$

'Department of Pharmacy, SMAS, Galgotias University, Greater Noida, U.P., India; ${ }^{2}$ Department of Pharmaceutical Chemistry, Faculty of Pharmacy, AIMST University, Kedah, 08I00, Malaysia;

${ }^{3}$ Department of Pharmacology, Faculty of Medicine, Bioscience and Nursing, MAHSA

University, Kuala Lumpur, 42610, Malaysia;

${ }^{4}$ Department of Biotechnology, Faculty of Applied

Science, AIMST University, Kedah, 08I00, Malaysia;

${ }^{5}$ Department of Physiology, Faculty of Medicine,

AIMST University, Kedah, 08I00, Malaysia;

${ }^{6}$ Department of Pharmacology, College of

Pharmacy, National University of Science and

Technology, Muscat, I30, Oman; 'Department of

Pharmacognosy, Faculty of Pharmacy, Tishk

International University, Erbil, 4400I, KRG, Iraq;

${ }^{8}$ Department of Pathology, Jeffrey Cheah School of

Medicine and Health Sciences, Monash University,

Johor Bahru, 80200, Malaysia; 'Department of

Pathology, Faculty of Medicine, Bioscience and

Nursing, MAHSA University, Kuala Lumpur, 42610,

Malaysia

*These authors contributed equally to this work
\end{abstract}

Correspondence: Neeraj Kumar Fuloria Department of Pharmaceutical

Chemistry, Faculty of Pharmacy, AIMST

University, Kedah, 08100, Malaysia

Tel +60 164037685

Email neerajkumar@aimst.edu.my

Shivkanya Fuloria

Department of Pharmaceutical

Chemistry, Faculty of Pharmacy, AIMST

University, Kedah, 08100, Malaysia

Tel +60 I43034057

Email shivkanya_fuloria@aimst.edu.my
Purpose: The present study was intended to fabricate chitosan (Ch)-tamarind gum polysaccharide (TGP) polyelectrolyte complex stabilized cubic nanoparticles of simvastatin and evaluate their potential against human breast cancer cell lines.

Materials and Methods: The antisolvent precipitation method was used for formulation of nanoparticles. Factorial design $\left(3^{2}\right)$ was utilized as a tool to analyze the effect of $\mathrm{Ch}$ and TGP concentration on particle size and entrapment efficiency of nanoparticles.

Results: Formulated nanoparticles showed high entrapment efficiency $(67.19 \pm 0.42-83.36$ $\pm 0.23 \%)$ and small size $(53.3-383.1 \mathrm{~nm})$. The present investigation involved utilization of two biological membranes (egg and tomato) as biological barriers for drug release. The study revealed that drug release from tomato membranes was retarded (as compared to egg membranes) but the release pattern matched that of egg membranes. All formulations followed the Baker-Lansdale model of drug release irrespective of the two different biological barriers. Stability studies were carried out for 45 days and exhibited less variation in particle size as well as a reduction in entrapment efficiency. Simvastatin loaded PEC stabilized nanoparticles exhibited better control on growth of human breast cancer cell lines than simple simvastatin. An unusual anticancer effect of simvastatin nanoparticles is also supported by several other research studies.

Conclusion: The present study involves first-time synthesis of Ch-TGP polyelectrolyte complex stabilized nanoparticles of simvastatin against MCF-7 cells. It recommends that, in future, theoretical modeling and IVIVC should be carried out for perfect designing of delivery systems.

Keywords: polysaccharide, polyelectrolyte, cubic nanoparticles, simvastatin, breast cancer, tamarind

\section{Introduction}

Abnormal growth and uncontrolled division of cells is known as cancer. Studies suggest that breast cancer is the second most common cancer after skin cancer. Breast cancer may spread into other organs of the body and becomes life-threatening. ${ }^{1}$ Conventional treatment of cancer involves radiotherapy, chemotherapy, and surgery. Several cancer treatment approaches are often ineffective, as attributed to their side-effects. Natural anticancer agents offering minimal side-effects are of great interest to many investigators. Studies suggest the anticancer potential of bio constituents of tamarinds seeds. ${ }^{2,3}$ 
Simvastatin is now the second most significant reductase inhibitor in the class of compounds known as hydroxy-methylglutaryl-coenzyme, a reductase inhibitor researched in humans. Simvastatin is now being provided for periods of up to 2 years to over 1,800 patients for the management of hypercholesterolemia. ${ }^{4}$

In a study examining the effect of simvastatin on hepatocellular carcinoma, it was observed that simvastatin induces G0/G1 arrest by upregulation of $\mathrm{p} 21$ and $\mathrm{p} 27$ by activation of AMPK and inhibition of the STAT3-Skp2 axis, respectively. ${ }^{5}$

Simvastatin also triggered caspase-dependent apoptosis in A549 lung cancer cells, where that was associated with decreased expression of phosphorylate Akt and lowregulatory survival of mRNA and protein. ${ }^{6}$ Another research study on prostate cancer using microarrays demonstrated that simvastatin therapy resulted in an upregulation of Annex A10 (ANXA10) in PC-3 cells. ANXA10 is assumed to also have anti-tumor effects. ${ }^{6}$

Tamarind (Tamarindus indica) belongs to the Fabaceae family and is widely distributed in India, especially South India. The tamarind gum polysaccharide (TGP) is extracted from the kernel of tamarind seeds. The TGP is also known as galactoxyloglucan and its molecular weight is around $52,350 \mathrm{D}$, which constitutes about $60 \%$ of the total seed content. ${ }^{7}$ The TGP exhibits good gelling ability and muco-adhesion properties. The TGP is used as a carrier for oral and parenteral drug delivery systems. ${ }^{8,9}$ In liquid dosage form, TGP has been used as suspending, emulsifying, and thickening agents. Moreover, TGP is also known for its nontoxic, biodegradability and biocompatibility properties. ${ }^{10}$ As discussed by authors in previous studies, a major component of tamarind seed pulp is carbohydrate $(70.8 \%)$, followed by protein $(3.1 \%)$ and fiber (3.0\%). Tamarind seed polysaccharide consists of the -OH group attached with cyclic structure. Galactose, xylose, and glucose are present in a 3:1:2 molar ratio. This ratio predicts that galactose is the major component of tamarind seed polysaccharide followed by glucose and xylose. ${ }^{9,11,12}$

Chitosan (Ch) is obtained from chitin. Crustacean and insect cuticle exoskeletons are known as rich natural sources of chitin. Chitin a natural biopolymer, is also found in fungal cell walls and mollusk shells. ${ }^{13}$ Tailoring of Ch by involving amino, acetamide, or hydroxy groups can generate derivatives with improved solubility and remarkable anticancer activity. ${ }^{14,15}$

Studies have shown that both $\mathrm{Ch}$ and its derivatives selectively permeate through cancer cell membranes and exhibit anticancer activity via enzymatic, immunoenhancing, antiangiogenic, antioxidant defense mechanisms, and the apoptotic pathways of cells. ${ }^{15}$ Wimardhani et al's study revealed that cell cycle arrest and induction of apoptosis is the basic reason behind the anticancer activity of $\mathrm{Ch}^{16}$

The hydrophobicity of therapeutic agents limits the bioactivity of potential biological molecules. Drug bioavailability is a major concern for the therapeutic efficacy of anticancer drugs. ${ }^{17,18}$

Investigation suggests that nanoparticles are a promising tool for enhancement of cancer treatment because of their bioavailability enhancement property. ${ }^{19}$ Nanoparticles are reported to enhance the bioavailability of less water-soluble drugs and prevent their degradation from various environmental factors. Nano-encapsulation is a novel approach to improve the solubility of dissolution controlled hydrophobic biologically active compounds. ${ }^{20}$

Since the last century, polyelectrolyte complex (PEC) based drug delivery systems have attracted researchers on the basis of their pharmaceutical and biomedical applications. One study reported the complex formation of $\mathrm{Ch}$ with a natural polymer (alginate) to retard the swelling and erosion of $\mathrm{Ch}$ that leads to retardation in drug release. ${ }^{21}$ The PEC formation is a novel strategy used to elevate the biological and pharmaceutical properties of polymers. ${ }^{22}$

The PEC formation and nanotechnology approach, combined, have been used by researchers to improve the bioavailability of active pharmaceutical ingredients (APIs). ${ }^{23}$ Rajabi et al developed Ch-gum Arabic polyelectrolyte based nanocarriers for the delivery of saffron bioactive compounds. Prepared nano capsules were spherical in shape, with a diameter of about $193 \mathrm{~nm}^{24}$ When oppositely charged macromolecules are allowed to interact with each other, polyelectrolyte or poly salt complexes are formed. Between oppositely charged molecules, like drugpolymer or polymer-polymer or polymer-drug-polymer, a few association complexes are formed, which are called PECs. Between these oppositely charged polyelectrolytes the electrostatic interaction may take place. ${ }^{25}$ PECs have been used to prepare systems for drug delivery. ${ }^{26}$

Structurally, these are neutral polymer-polymer complexes consisting of macromolecules with opposite charges causing the electrostatic interactions to bind macromolecules together. In PEC formation, ion dipole interactions, hydrogen bonding and hydrophobic interactions play a major role. This complexity leads to the loss of polymer chain conformation and translational entropy that must be counter-balanced. Electrostatic force is 
considered a major contributor to the formation of PECs. However, other components of hydrogen bonding in dipole forces and hydrophilic interaction also significantly contribute to their complexation process. ${ }^{27,28}$ When low molecular weight counter ions are released, there is a gain in entropy. It is the main driving force for complex formation. In recent decades, researchers have tried to develop PEC stabilized nanoparticles for drug delivery. The shape of the nanoparticles is a key factor that affects biodistribution, bio-circulation, cellular penetration, and targeting sites. In most of the cases nanoparticles are spherical in shape, maybe due to less awareness about the effect of shape of formulation on therapeutic effect and simplicity of process. Recently, the focus of biomedical scientists, globally, has shifted towards the shapespecific fabrication of nanoparticles. The shape of nanoparticles also dictates the fate of pharmacokinetics and pharmacodynamics of active pharmaceutical ingredients. In recent decades, the formulation of cubic nanoparticles has attracted much attention. Fabrication of cubic nanoparticles has tuned the association of particles with specific receptors. Research claims that the PRINT method has been used to prepare cube-shaped nanoparticles. Also, the solvent-antisolvent precipitation method assists in the preparation of spherical nanoparticles. ${ }^{29,30}$

It was observed that none of the researchers used solvent-antisolvent precipitation method for the fabrication of Ch-TGP polyelectrolyte stabilized cubic nanoparticles. Interaction between the amino group of $\mathrm{Ch}$ and the hydroxyl group of TGP leads to formation of PECs. As PECs are formed between biocompatible, biodegradable, and nontoxic polymers, they are expected to offer good bio-acceptability. Self-organization, reversible and spontaneous association between oppositely charged molecules without covalent cross-linkers is a distinguished feature of formed PECs. Formed PECs are biodegradable, biocompatible, and non-toxic in nature. The study of Verma et al found that formation of PECs between poly acid and poly base leads to the formation of crystal-like structures. ${ }^{31}$

Keeping with the idea of Verma et al, it was expected that $\mathrm{Ch}$ - and TGP-based PECs will produce crystalline nanoparticles. ${ }^{31}$ As per our knowledge, it was the first attempt to explore the formulation of Ch-TGP polyelectrolyte stabilized crystalline nanoparticles for therapeutic application. Limited information was found on the effect of shape of polyelectrolyte stabilized nanoparticles on human cancer cells. In the present study, an attempt was made to investigate the effect of cubic nanoparticles and needle-shaped pure drugs in human breast cancer cell lines. The outcomes of the study will surely provide basic guidelines for the design of delivery systems against cancer.

\section{Materials and Methods General}

The chemicals, reagents and solvents were obtained from Merck Specialties, Sigma Aldrich, S D Fine Chemicals Limited, Fisher Chemicals, and HiMedia. Chitosan (medium molecular weight, $75-85 \%$ deacetylated) was procured from Sigma Aldrich, St. Louis, USA).

\section{Extraction of Tamarind Gum Polysaccharide}

The testa (seed coat) of the seeds of tamarind was removed by drying them in a hot air oven for $20 \mathrm{~min}$ at $40^{\circ} \mathrm{C}$. Next, the seed coating was removed by simply crushing the seeds from one side. Obtained white portions of the seeds were then utilized for the isolation of gum. The inner white part of seeds was immersed in a beaker with double-distilled water and heated at $40^{\circ} \mathrm{C}$ for $2 \mathrm{~h}$. The supernatant fluid was discarded after centrifugation. Further, the remaining portion was concentrated by again heating at a constant temperature of $40^{\circ} \mathrm{C}$. The slurry was filtered, and filtrate was precipitated using ethyl alcohol. The precipitated product was spread on the petri dish, dried and the size was reduced till a fine powder was obtained. Size reduction was carried out using a pestle and mortar. The powder was passed through sieve \#22 and stored for further use. ${ }^{32}$

\section{Factorial Design}

The $3^{2}$ factorial design was used to prepare nanoparticles. In the present research, TGP and Ch concentrations were selected as independent variables; for dependent variables, particle size and entrapment efficiency were selected. Three levels were selected for every independent variable, as shown in Table 1 . The NCSS 12 software (Trial version $15 / 05 / 2018$ ) was used for the analysis of dependent variables. $^{33}$

\section{Preparation of PEC Stabilized Nanoparticles}

Nanoparticles were formulated using various concentrations of TGP and $\mathrm{Ch}$, as shown in Table 1 . Solutions of $20 \mathrm{~mL} \mathrm{TGP}$ and $20 \mathrm{~mL}$ of $\mathrm{Ch}$ were 
Table I Concentration of TGP (\% w/v) and Ch (\% w/v) for the Preparation of Nanoparticles

\begin{tabular}{|l|c|c|}
\hline S. No. & TGP (\%w/v) & Chitosan (\%w/v) \\
\hline 1 & 0.03 & 0.03 \\
2 & 0.03 & 0.01 \\
3 & 0.03 & 0.02 \\
4 & 0.01 & 0.03 \\
5 & 0.01 & 0.01 \\
6 & 0.01 & 0.02 \\
7 & 0.02 & 0.03 \\
8 & 0.02 & 0.01 \\
9 & 0.02 & 0.02 \\
\hline
\end{tabular}

prepared separately in distilled water and 5\% glacial acetic acid, respectively. TGP solution was further transferred into $\mathrm{Ch}$ solution and stirred for $20 \mathrm{~min}$ at $40^{\circ} \mathrm{C}$ and for a further $5 \mathrm{~min}$ at $50^{\circ} \mathrm{C}$. Simvastatin solution $(1 \mu \mathrm{g} / 1 \mathrm{~mL})$ was prepared using acetone as solvent. For the preparation of simvastatin solution, $10 \mathrm{mg}$ simvastatin was solubilized into $10 \mathrm{~mL}$ of acetone, followed by serial dilution to prepare $1 \mu \mathrm{g} / 1 \mathrm{~mL}$ solution. The drug solution $(5 \mathrm{~mL})$ was further added dropwise into the previously prepared TGP-Ch solution (PEC solution) using a syringe (BD Emerald, $5 \mathrm{~mL}$ ). Next, the solution was stirred for $45 \mathrm{~min}$ at $65^{\circ} \mathrm{C}$. Finally, the sample was cooled to $35^{\circ} \mathrm{C}$ and kept in an airtight container. ${ }^{34}$ Prepared samples consisting of dispersions of nanoparticles were used for further study and nanoparticles were not separated from the dispersions.

In the present investigation, simvastatin solution $(1 \mu \mathrm{g} /$ $1 \mathrm{~mL}$ ) was prepared using acetone as solvent. For the preparation of simvastatin solution, $10 \mathrm{mg}$ simvastatin was solubilized into $10 \mathrm{~mL}$ of acetone, followed by serial dilution to prepare a $1 \mu \mathrm{g} / 1 \mathrm{~mL}$ solution.

Prepared samples consisting of a dispersion of nanoparticles (nanosuspension) were used for further study and nanoparticles were not separated from the dispersion. As the final formulation was nanosuspension, washing was not performed.

\section{FTIR Spectral Analysis}

Spectral analysis of native polymers (Ch and TGP), a drug (simvastatin) and a physical mixture of $\mathrm{Ch}$, TGP and simvastatin was done to identify any interaction between drug and polymer. Analysis of all the compounds was done using OPUS software to record the spectra in the range $4000-400 \mathrm{~cm}^{-1}$.

\section{Nanoparticles Evaluation}

Based on the following parameters, the PEC-based nanoparticles were characterized.

\section{Physical Appearance}

All the nanoparticles prepared were visually checked for turbidity. ${ }^{35}$

\section{Particle Size Study}

Using Zetasizer (Malvern Instruments, model no. 2000), the particle size of the formulated nanoparticles was determined. Zeta potential was also determined along with particle size. For the analysis, a dilute solution of $1 \%$ was used. ${ }^{36}$ As discussed in various literatures, concentrated solutions may create problems during particle size analysis. In the present investigation, a zeta analyzer was used to determine the particle size of THE formulated nanosuspension. A zeta analyzer is based on the principle of dynamic light scattering (DLS). In the concentrated solution, multiple scattering may take place that further leads to false results. To avoid the chance of false measurement, dilute solutions are generally employed to determine the size of suspended particles. ${ }^{37,38}$

\section{Surface Properties}

The SEM is primarily used for the determination of the sample morphology. The morphology of the nanoparticles was analyzed by the Zeiss EVO 18 analyzer. The powder was coated with gold and then placed in a sample holder. Nanosuspensions were kept in a sample holder and dried under vacuum, before analysis to prepare powder. The surface properties of PEC stabilized nanoparticles were determined by a different magnification process. ${ }^{39}$

\section{Entrapment efficiency}

Absorption analysis of all formulations was carried out via the drug calibration plot to measure entrapment efficiency (\%). In order to calculate entrapment efficiency, equation 1 was used. The freshly prepared $10 \mathrm{~mL}$ portion of the cooled nanosuspension was centrifuged in microcentrifuge at $10,000 \mathrm{rpm}$ for $10 \mathrm{~min}$. The supernatant was extracted, and the quantity of un-incorporated drug was calculated based on absorption of supernatant solution at $238 \mathrm{~nm}$ recorded using a UV spectrophotometer (UV-1800, Shimadzu, Japan). ${ }^{40,41}$

$$
\text { Entrapment Efficiency }(\%)=\frac{\text { Total drug }- \text { Free drug }}{\text { Total drug }} \times 100
$$

\section{Drug Release}

Tomato membranes and egg-shell membranes were used to determine the drug release from different formulations prepared from PECs. ${ }^{42}$ 


\section{Membrane Preparation \\ Egg Membrane Preparation}

The chicken egg was taken for the preparation of the egg membrane. An orifice was created at one end of the egg and the yolk was completely removed through the opening. The egg shell was kept in a beaker containing a solution of distilled water and $0.1 \mathrm{~N} \mathrm{HCl}$ (3:1 ratio). The egg shell containing calcium carbonate was released as foam when it came in contact with an acidic solution (equation 2). The temperature of the solution was raised to $50^{\circ} \mathrm{C}$, which created bubbles. The bubbles stopped after 45 min and the foam disappeared. At last, only the egg membrane was left in the beaker. ${ }^{33}$

$$
\mathrm{CaCO}_{3}+2 \mathrm{HCl} \rightarrow \mathrm{CaCl}_{2}+\mathrm{CO}_{2}+\mathrm{H}_{2} \mathrm{O}
$$

\section{Preparation of Tomato Membrane}

At the top of the tomato fruit a cross was made to release the pulp. The tomato was heated in a water bath at $50^{\circ}$ $\mathrm{C}$ for $5 \mathrm{~min}$ and the membrane was then removed slowly and carefully. ${ }^{43}$

\section{In vitro Drug Release}

Formulation was enclosed in the biological membrane (tomato and egg membranes) and tied properly. To enclose the formulation, a $2 \mathrm{~cm} \mathrm{x} 3 \mathrm{~cm}$ membrane was cut and used. Initially, drug release was carried out in $0.1 \mathrm{~N} \mathrm{HCl}$ for $2 \mathrm{~h}$ followed by release study in a phosphate buffer $\mathrm{pH}$ 7.4 up to $24 \mathrm{~h}$. The temperature of both mediums was maintained at $37 \pm 0.5^{\circ} \mathrm{C}$ during the study, at $25 \mathrm{rpm}$. A sample $(5 \mathrm{~mL})$ was withdrawn at fixed time intervals and the same volume of fresh buffer was added. A UV spectrophotometer (UV-1800, Shimadzu, Japan) at wavelength $238 \mathrm{~nm}$ was used for the analysis. Equation 3 was used to determine drug release $(\%) .^{32,44}$

$$
\text { Drug release }(\%)=\frac{\begin{array}{l}
\text { Concentration in formulation } \times \\
\text { Dilution factor } \times \text { Bath volume }
\end{array}}{1000} \times 100
$$

\section{Kinetic Studies of Drug Release}

It is always necessary to determine the dissolution profile of a formulation. Kinetic models are used to determine the dissolution of a drug from the formulation in which the quantity of a dissolved drug is the function of time. ${ }^{45,46}$ Release kinetics can be influenced by the particle size of drug, type of drug, and solubility of drug. Kinetic study ensured that dissolution was occurring in the proper manner. To study the kinetics of drug release from the controlled release formulation, statistical methods and modeldependent methods were used. Model-dependent approaches included zero order, first order, HixsonCrowell, Higuchi, Baker-Lonsdale, and KorsmeyerPeppas. ${ }^{47,48}$ To calculate the zero-order and first-order rate constants, equations 4 and 5 were used, respectively.

$$
Q_{t}=Q_{o}+K_{o} t
$$

where Qt is the drug dissolved amount in time $t ; \mathrm{Q}_{0}$ is the initial amount of drug in the solution; and $\mathrm{K}_{0}$ is the zeroorder release constant, which is stated in units of concentration/time.

$$
\frac{d C}{d T}=-K c
$$

where $\mathrm{K}$ is the first-order rate constant (time ${ }^{-1}$ ).

Equation 6 was used to determine the rate constant of the Higuchi model.

$$
f_{t}=Q=A=\sqrt{\frac{D \delta}{\tau}\left(2 C-\delta C_{S}\right) C_{S} t}
$$

where $\mathrm{Q}$ is the released amount of the drug in time " $\mathrm{t}$ " per unit area $\mathrm{A}$; $\mathrm{C}$ is the initial concentration of the drug; $\mathrm{C}_{\mathrm{s}}$ is the solubility of the drug in the matrix media; and $\mathrm{D}$ is the drug molecule diffusivity.

To determine the kinetics of the Hixson-Crowell model release, equation 7 was used.

$$
W_{o}^{\frac{1}{3}}-W_{t}^{\frac{1}{3}}=\kappa t
$$

where $\mathrm{W}_{0}$ is the initial drug amount in the pharmaceutical dosage form and $\mathrm{W}_{\mathrm{t}}$ is the remaining drug amount in the pharmaceutical dosage form at time $t$.

The release rate constant was determined by equation 8 for the Korsmeyer-Peppas model.

$$
\frac{M_{t}}{M_{\infty}}=K t^{n}
$$

where $\mathrm{Mt} / \mathrm{M} \infty$ is a drug fraction released at time $\mathrm{t} ; \mathrm{k}$ is the release rate constant; $\mathrm{n}$ is the release exponent; and $\kappa$ (kappa) is a constant incorporating the surface volume relation.

Equation 9 was used to determine the rate constant for the Baker-Lonsdale model. 


$$
f_{1}=\frac{3}{2}\left[1-\left(1-\frac{M_{t}}{M_{\infty}}\right)^{\frac{2}{3}}\right] \frac{M_{t}}{M_{\infty}}=k_{t}
$$

where the release rate constant, $\mathrm{k}$, corresponds to the slope.

\section{Similarity Factor}

In formulation and dossier preparation, the concept of the similarity factor $\left(f_{2}\right)$ has been widely adopted. Two new indices $\left(f_{1}\right.$ and $f_{2}$ ) were proposed by Moore and Flanner to compare test dissolution profiles and a reference formulation expressed in equation $10 .^{49}$

$$
f_{2}=50 \log \left\{\left[1+\frac{1}{3} \sum_{n=1}^{n}\left(R_{t}-T_{t}\right)^{2}\right]^{-0.5} \times 100\right\}
$$

where $f_{2}$ is the similarity factor; $n$ is the observation number; and $\left(\mathrm{R}_{\mathrm{t}}-\mathrm{T}_{\mathrm{t}}\right)$ is the difference between the value of test and reference products.

\section{Stability Studies}

The growth of the particle size of PEC-based nanoparticles was also measured at $25 \pm 2^{\circ} \mathrm{C}$ by determining the particles' size on the 1st, 7 th, 14th and 21 st days and the possible growth of crystals. ${ }^{50}$

At $40 \pm 2{ }^{\circ} \mathrm{C}$ and $75 \pm 5 \% \mathrm{RH}$ for 45 days, stability studies were carried out. In terms of particle size and entrapment efficiency, the stability of formulations was determined. ${ }^{51}$

\section{Anticancer Activity}

Assessment of anticancer activity of samples was carried out at an anticancer screening facility, Tata Memorial Center, Mumbai, as described in previous studies. ${ }^{33,52,53}$

An in vitro cytotoxicity analysis of pure drug and optimized formulation T5 was performed against breast cancer cell lines (MCF7) at the anti-cancer drug screening facility (ACDSF) at ACTREC, Tata Memorial Centre, Navi Mumbai. Sulphorhodamine B (SRB) was employed for the activity.

In the present analysis, MCF-7 cells were incubated for $24 \mathrm{~h}$ at $37{ }^{\circ} \mathrm{C}$ in 96 -well microtiter plates. After inoculation of the cell, the microtiter plates were incubated with $5 \% \mathrm{CO}_{2}, 100 \%$ relative humidity and $95 \%$ air for $24 \mathrm{~h}$ at $37^{\circ} \mathrm{C}$ prior to addition of experimental drugs. Initially, test samples were solubilized in dimethyl sulfoxide at $100 \mathrm{mg} / \mathrm{mL}$ and diluted with water to $1 \mathrm{mg} / \mathrm{mL}$ and stored frozen prior to usage. A frozen concentrate $(1 \mathrm{mg} / \mathrm{mL})$ aliquot was thawed and dilutions of 2, 4, 8 and $10 \mu \mathrm{g} /$ $\mathrm{mL}$ test sample solutions were prepared. The plates were incubated for $48 \mathrm{~h}$ after the addition of the sample in the standard condition and, by the addition of cold trichloroacetic acid (TCA), reaction was terminated again. The cells were fixed by the gentle addition of $50 \mu \mathrm{L}$ of cold $30 \%$ (w/ v) TCA (final concentration, 10\% TCA) and further incubated at $4{ }^{\circ} \mathrm{C}$ for $60 \mathrm{~min}$. The supernatant was discarded; the plates were washed with tap water five times and air dried. Sulphorhodamine B (SRB) solution $(50 \mu \mathrm{L})$ at room temperature was added to each well at $0.4 \%(\mathrm{w} / \mathrm{v})$ in $1 \%$ acetic acid and the plates were incubated for $20 \mathrm{~min}$. Washing was done with $1 \%$ acetic acid solution for the removal of unbound dye and the plates were then dried. The bound stains were then eluted with $10 \mathrm{mM}$ Trizma base and the absorbance was read on a plate reader at a wavelength of $540 \mathrm{~nm}$ with a reference wavelength of $690 \mathrm{~nm}$. Percentage growth inhibition was calculated as shown in equation 11:

$$
\frac{\mathrm{Ti}}{C} \times 100 \%
$$

\section{Statistical Analysis}

Experimentation work was carried out in triplicate and obtained data was presented as an average of results with standard deviation. Data were subjected to one-way analysis of variance (ANOVA) and $t$-tests were applied to evaluate equality of means. A p-value of $>0.05$ was considered statistically insignificant.

\section{Results and Discussion}

Inter-chain interaction in the solvent between Ch and TGP leads to the formation of PECs driven by electrostatic interaction. Hydrogen bonding, dipole-dipole interaction and hydrophobic interaction also play an important role in the formation of PECs. Figure 1 shows the PEC formation between chitosan and tamarind gum polysaccharide.

The weak electrolyte and PEC formation of the $\mathrm{Ch}$ and TGP implies a reduction in the free energy of the system. It further improves the stability of the complex formed. All the PEC stabilized nanoparticles were prepared using TGP and Ch. As discussed in another study, for the complex formation, oppositely charged biopolymers are mixed in solution form. Concentration of polymers should be kept below gelling point. So, in the present study, both $\mathrm{Ch}$ and TGP were used in very low concentrations to avoid gel formation. ${ }^{54} \mathrm{In}$ the present research, a very low concentration of the drug 


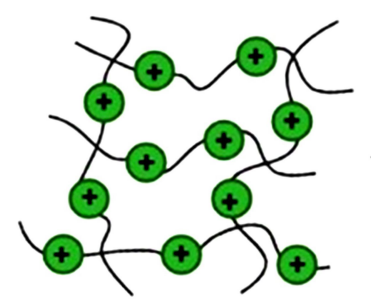

Chitosan

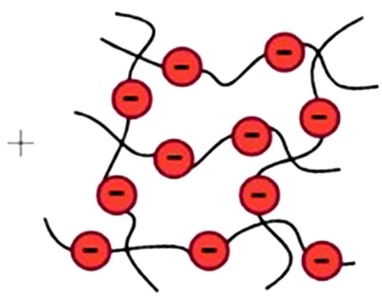

TGP

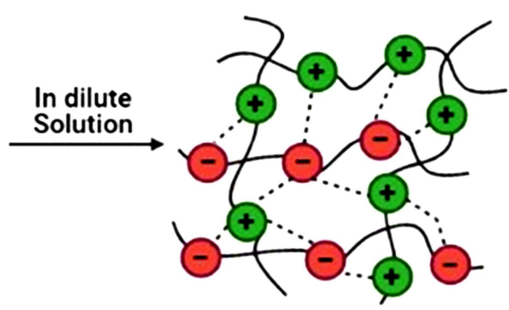

PEC

Figure I Schematic representation of PEC formation between chitosan and tamarind gum polysaccharide.

was used to investigate its unusual anticancer effect. In other research, investigators also used a very low concentration of the drug to identify its unusual effect. ${ }^{55}$

Most of the available information on nanoparticles is based on the spherical nature of nanoparticles. The solvent-antisolvent method maintains finer control over particle size distribution and is able to modulate particle geometry. Jindal et al identified that nanoparticles deviate from the spherical shape mainly due to solute-solvent or solute-solute interaction. ${ }^{56}$

Classically, nanoparticles were prepared by solvent evaporation and the emulsification method; in the present investigation, however, novel antisolvent methods were used for the preparation of PEC stabilized nanoparticles. In this method drug nano-precipitates were formed using the antisolvent system and further stabilized with PECs. IR interpretation of TGP data is shown in Table 2. IR interpretation of simvastatin data is shown in Table 3. IR interpretation of chitosan data is shown in Table 4. IR interpretation of IR spectra of the physical mixture of Ch, TGP and simvastatin is shown in Table 5. Figures 2 and 3 show the IR spectra of TGP and simvastatin. Figure 4 shows the IR spectra of chitosan and Figure 5 shows the IR spectra of the physical mixture of Ch, TGP and simvastatin.

The IR spectra of TGP shows that it contains O-H stretch, $\mathrm{COOH}, \mathrm{C} \equiv \mathrm{C}$ stretch, $\mathrm{C}=\mathrm{C}$ stretch, $\mathrm{C}-\mathrm{O}$, and N-H bend functional groups. Results of the IR spectral study weres also

Table 2 IR Interpretation of TGP

\begin{tabular}{|l|c|c|}
\hline S.No. & Wave Numbers $\mathbf{( c m}^{-\mathbf{1}} \mathbf{)}$ & Functional Groups \\
\hline 1 & 3616 & O-H Stretch \\
2 & $236 \mathrm{I}$ & COOH \\
3 & 2115 & C $=$ C Stretch \\
4 & 1646 & C=C Stretch \\
5 & 1042 & C-O \\
6 & 1515 & N-H Bend \\
\hline
\end{tabular}

supported by Chawananorasest et al's study showing that the average molecular weight of tamarind seed polysaccharide ranges from $700-880 \mathrm{kDa}^{9}{ }^{9}$ The IR spectra of simvastatin shows that it contains $\mathrm{N}-\mathrm{H}$ stretch, $\mathrm{C}-\mathrm{H}$ stretch, $\mathrm{C} \equiv \mathrm{O}$ stretch, $\mathrm{C}=\mathrm{C}$ stretch, $\mathrm{C}-\mathrm{H}$ bend, and $\mathrm{C}-\mathrm{N}$ bend functional groups. The IR spectra of chitosan shows that it contains $\mathrm{O}-\mathrm{H}$ stretch, $\mathrm{COOH}, \mathrm{C} \equiv \mathrm{C}$ stretch, $\mathrm{C}=\mathrm{C}$ stretch, $\mathrm{C}-\mathrm{O}$, and $\mathrm{N}-\mathrm{H}$ bend functional groups. The IR spectra of the physical mixture of $\mathrm{Ch}$, TGP and simvastatin shows that it contains $\mathrm{COOH}, \mathrm{C}-\mathrm{H}$ bend, $\mathrm{C}=\mathrm{C}$ stretch, $\mathrm{N}-\mathrm{O}$ stretch, $\mathrm{C}-\mathrm{O}$ stretch, and $\mathrm{C}=\mathrm{C}$ bend functional groups. The IR spectra shows that, significantly, no interaction occurs between the functional groups of the physical mixture of $\mathrm{Ch}$, TGP and simvastatin.

\section{Factorial Design}

In the present research,a $3^{2}$ factorial design was used to evaluate the effect of independent variables (concentration of TGP and Ch) over particle size and the entrapment efficiency of nanoparticles (dependent variable). A reduced equation for measuring response (particle size and entrapment efficiency) with statistical significance for the $3^{2}$ factorial design is shown as equation 12 .

$$
y=b_{0}+b_{1} x_{1}+b_{2} x_{2}+b_{12} x_{1} x_{2}+b_{11} x_{12}+b_{22} x_{22}
$$

where $\mathrm{Y}=$ response of variables (dependent variables); $\mathrm{b}_{0}=$ arithmetic mean response of nine batches; and $b_{1}=$ estimated

Table 3 IR Interpretation of Simvastatin

\begin{tabular}{|l|c|c|}
\hline S.No. & Wave Numbers $\mathbf{( c m}^{-\mathbf{1}} \mathbf{)}$ & Functional Groups \\
\hline 1 & 3645 & N-H Stretch \\
2 & 2921 & C-H Strech \\
3 & 1698 & C $\equiv$ O Stretch \\
4 & 1510 & C=C Stretch \\
5 & 1384 & C-H Bend \\
6 & 1271 & C-N Bend \\
7 & 867 & C-H Bend \\
\hline
\end{tabular}


Table 4 IR Interpretation of Chitosan

\begin{tabular}{|l|c|c|}
\hline S.No. & Wave Numbers $\mathbf{( c m}^{-\mathbf{1}} \mathbf{)}$ & Functional Groups \\
\hline 1 & 3616 & $\mathrm{O}-\mathrm{H}$ Stretch \\
2 & $236 \mathrm{I}$ & $\mathrm{COOH}$ \\
3 & 2115 & $\mathrm{C} \equiv \mathrm{C}$ Stretch \\
4 & 1646 & $\mathrm{C}=\mathrm{C}$ Stretch \\
5 & 1042 & C-O \\
6 & 1515 & N-H Bend \\
\hline
\end{tabular}

Table 5 IR Interpretation of IR Spectra of the Physical Mixture of Ch, TGP and Simvastatin

\begin{tabular}{|l|c|c|}
\hline S. No. & Wave Numbers $\mathbf{( c m}^{-\mathbf{1}} \mathbf{)}$ & Functional Groups \\
\hline $\mathrm{I}$ & $236 \mathrm{I}$ & $\mathrm{COOH}$ \\
2 & 1832 & C-H Bend \\
3 & 1648 & C=C Strech \\
4 & 1522 & N-O Stretch \\
5 & 1108 & C-O Stretch \\
6 & 758 & C=C Bend \\
\hline
\end{tabular}

coefficient of factors $X_{1}$. The coefficient corresponding liner effect $\left(b_{1}\right.$ and $\left.b_{2}\right)$, interaction $\left(b_{1}\right)$ and quadratic effect $\left(b_{1}\right.$ and $b_{2}$ ) were determined from the results of the experiment; and $\mathrm{X}_{1}$ and $\mathrm{X}_{2}$ are quantity of the polymers.

Solving equation 12 makes it possible to generate the effect of quantity of polymer over particle size (equation 13) and the entrapment efficiency (equation 14) of nanoparticles.

$$
\begin{aligned}
\mathrm{PS}= & 180.155+65.85\left(X_{1}\right)+22.98\left(X_{2}\right)+0.366\left(X_{1} X_{2}\right) \\
& +30.52\left(X_{12}\right)-2.11\left(X_{22}\right)
\end{aligned}
$$

where PS $=$ particle size in $\mathrm{nm}$.

$$
\begin{aligned}
\mathrm{EP}(\%)= & 76.77-1.72\left(X_{1}\right)+0.46\left(X_{2}\right)-1.03\left(X_{1} X_{2}\right) \\
& -0.815\left(X_{12}\right)+0.098\left(X_{22}\right)
\end{aligned}
$$

In the present study, only two levels of each factor were shown in equations because the third level of each factor did not significantly affect the overall outputs of the independent variables. To simplify the equation, only two levels are shown in the text.

The surface plots for effect of independent variables over size and entrapment efficiency of nanoparticles are shown in Figures 6 and 7, respectively.

\section{Characterization of PEC Stabilized Nanoparticles of Simvastatin}

The formulations of nanoparticles were prepared using PEC, checked visually and found to be clear. The prepared nanosuspensions were found to be transparent without any precipitation (Table 6). The particle size of all formulations was observed to be in the range of 53.3 to $383.1 \mathrm{~nm}$. The smallest particle size was observed in the case of formulation T5 $(53.3 \mathrm{~nm})$ as it contains the lowest concentration of TGP and Ch. Formulation T1 shows the largest particle size, 383.1 $\mathrm{nm}$, which may be due to the highest concentration of TGP

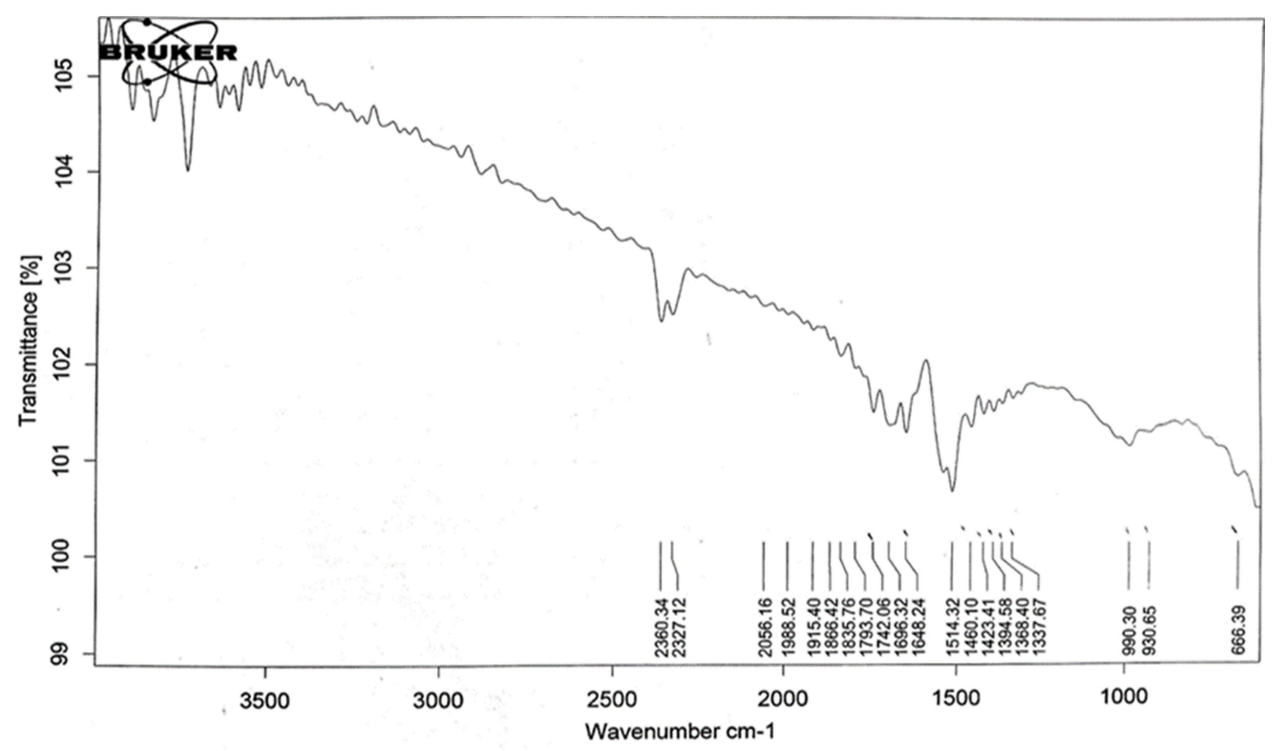

Figure 2 IR spectra of TGP. 


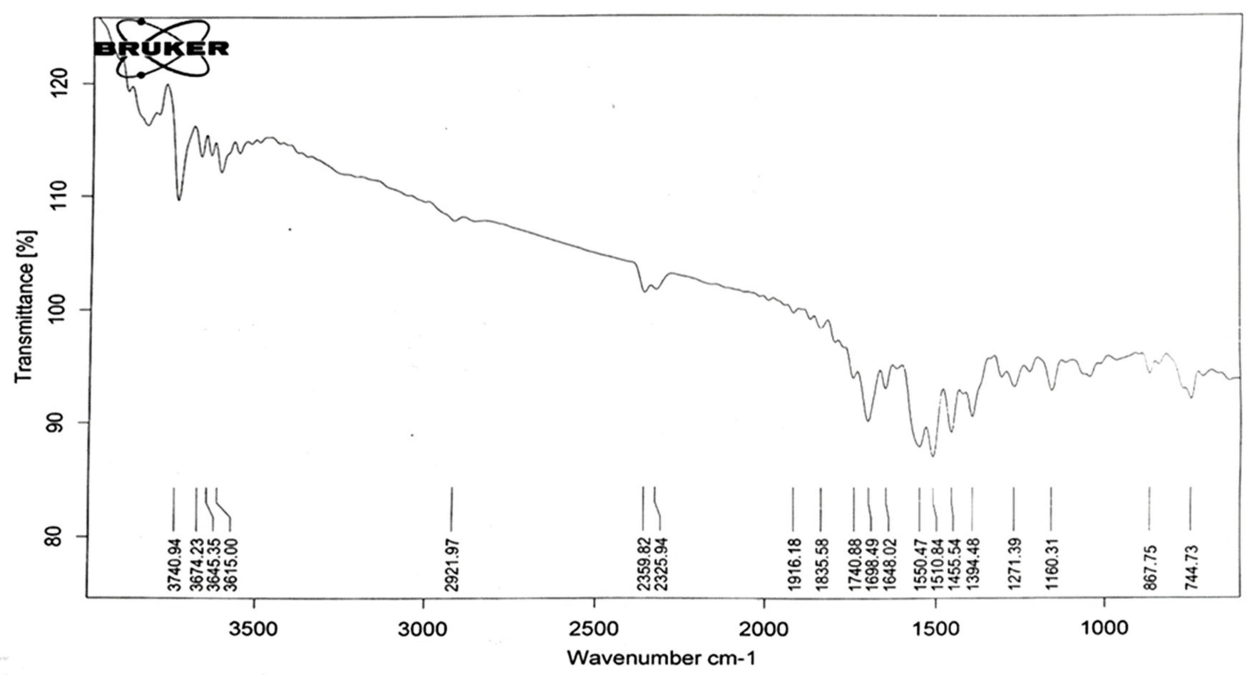

Figure 3 IR spectra of simvastatin.

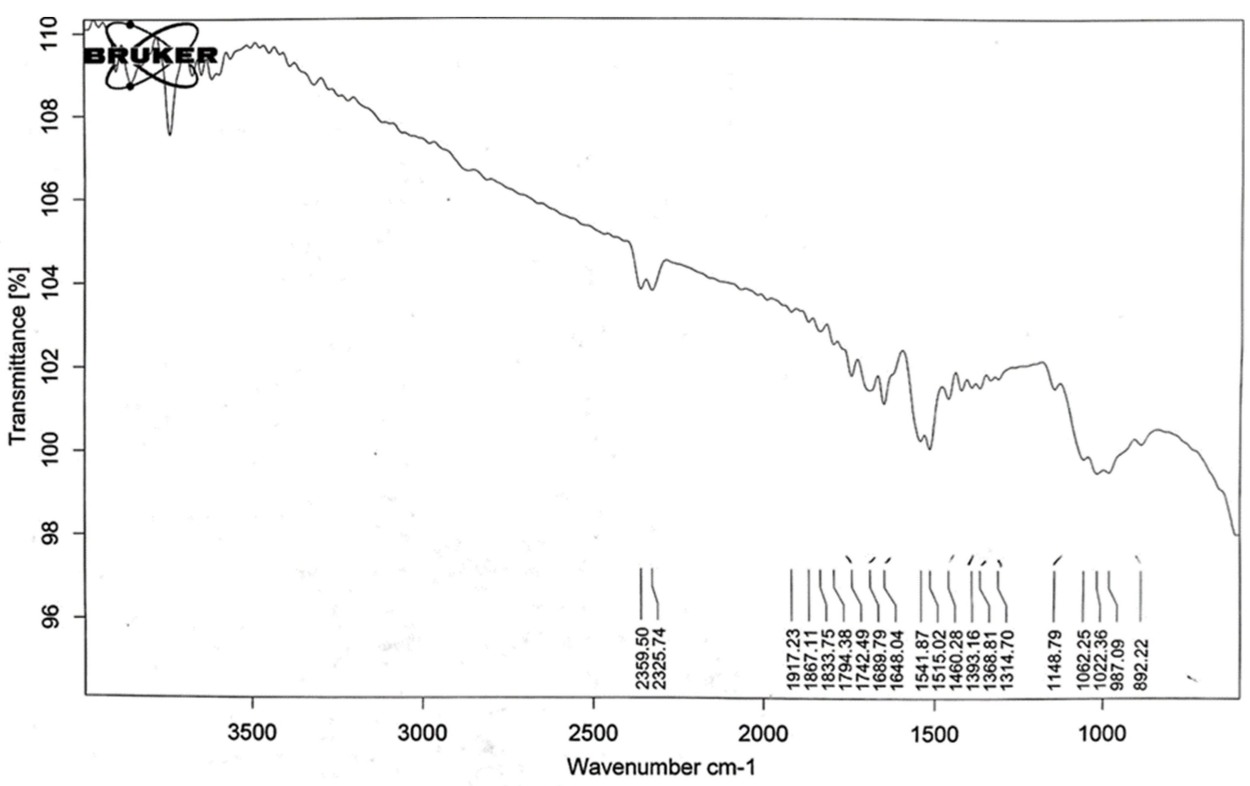

Figure 4 IR spectra of chitosan.

and $\mathrm{Ch}$. The surface volume ratio of the non-spherical particles (like cubic and rod-shaped) is less than that of the spherical particles. Results obtained in the present study were also supported by Oh et al's study, wherein the particles having a lower aspect ratio show better cytotoxicity. ${ }^{57}$

Perfect designing of nanoformulations should justify high entrapment efficiency, smaller particle size, no or less drug leaching and improved bioavailability. As discussed by many researchers, nanoparticles with a size range of less than $100 \mathrm{~nm}$ are capable of entering and remaining within tumor cells and have better therapeutic potential. Small size nanoparticles are selectively accumulated within the tumor cells when distribution takes place. A study by Jansch et al revealedha that the shape of the nanoparticles does not affect the protein binding of formulations. ${ }^{58}$ Moore et al found that particle sizes below $100 \mathrm{~nm}$ have the ability to drift towards the capillary wall (due to hydrodynamics) and show better cellular accumulation. ${ }^{59}$ Another study found that cellular internalization of nanorods was not significantly altered by the aspect ratio. ${ }^{60}$ Circulation of nonspherical nanoparticles in blood is significantly affected by the orientation of particles in vessels. Vacha et al observed 


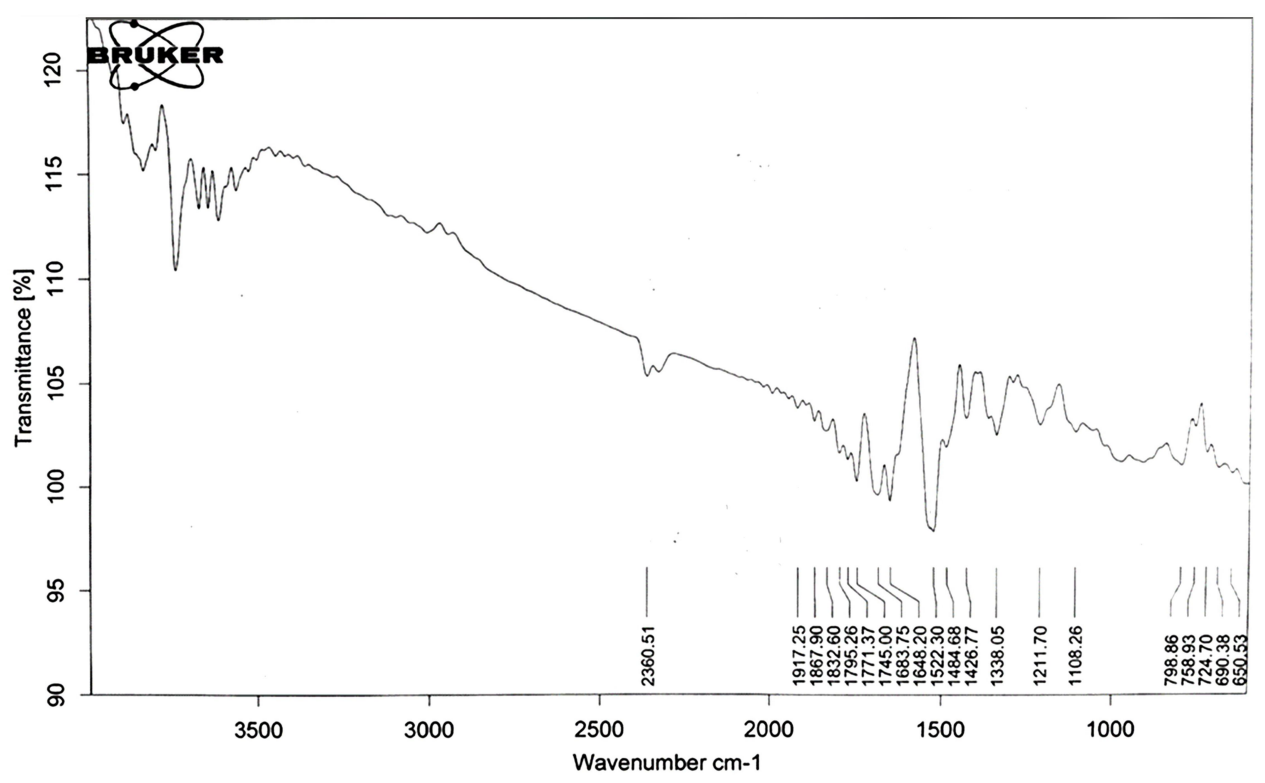

Figure 5 IR spectra of the physical mixture of Ch, TGP and simvastatin.

that surface adhesion energy is the key determining factor for the endocytosis of nanoparticles. ${ }^{61}$ The T5 was considered the optimal formulation as it has the lowest particle size $(53.3 \mathrm{~nm})$. The T5 was further used for the characterization of the in vitro anticancer effect. The potential difference on the surface of nanoparticles was determined. The zeta potential is the electrical potential at the slipping plane location in the interfacial double layer, which is a relative point in the bulk fluid away from the interface. The potential difference between the dispersion medium and the stationary layer of fluid attached to the dispersed particle is zeta potential. Zeta potential was observed in the range of 32.2 $\mathrm{mV}$ to $34.3 \mathrm{mV}$. Formulation $\mathrm{T} 1$ shows the largest particle size but lowest zeta potential, $32.2 \mathrm{mV}$. It may be due to charge neutralization, as both TGP and Ch contain the highest concentration, so their charge neutralizes and results in

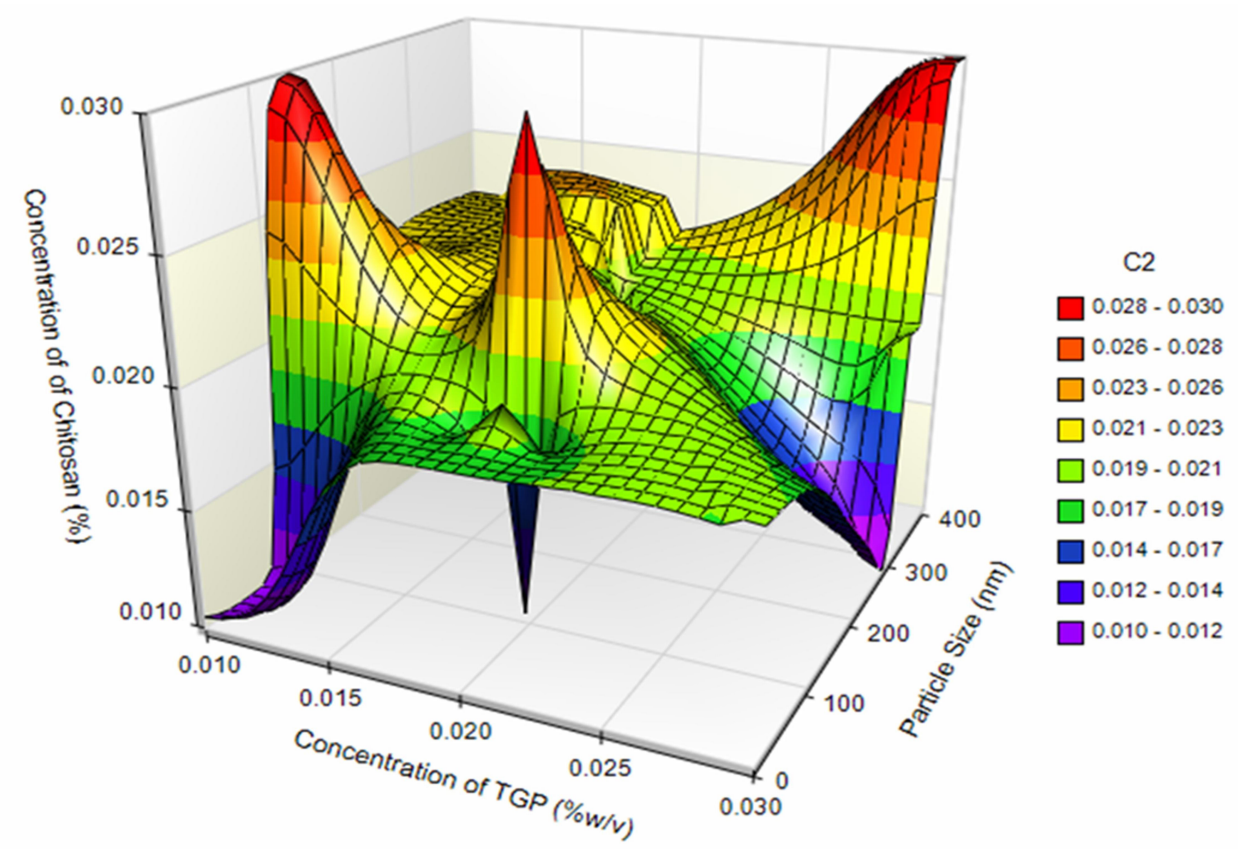

Figure 6 Surface plot for effect of independent variables over size of nanoparticles. 


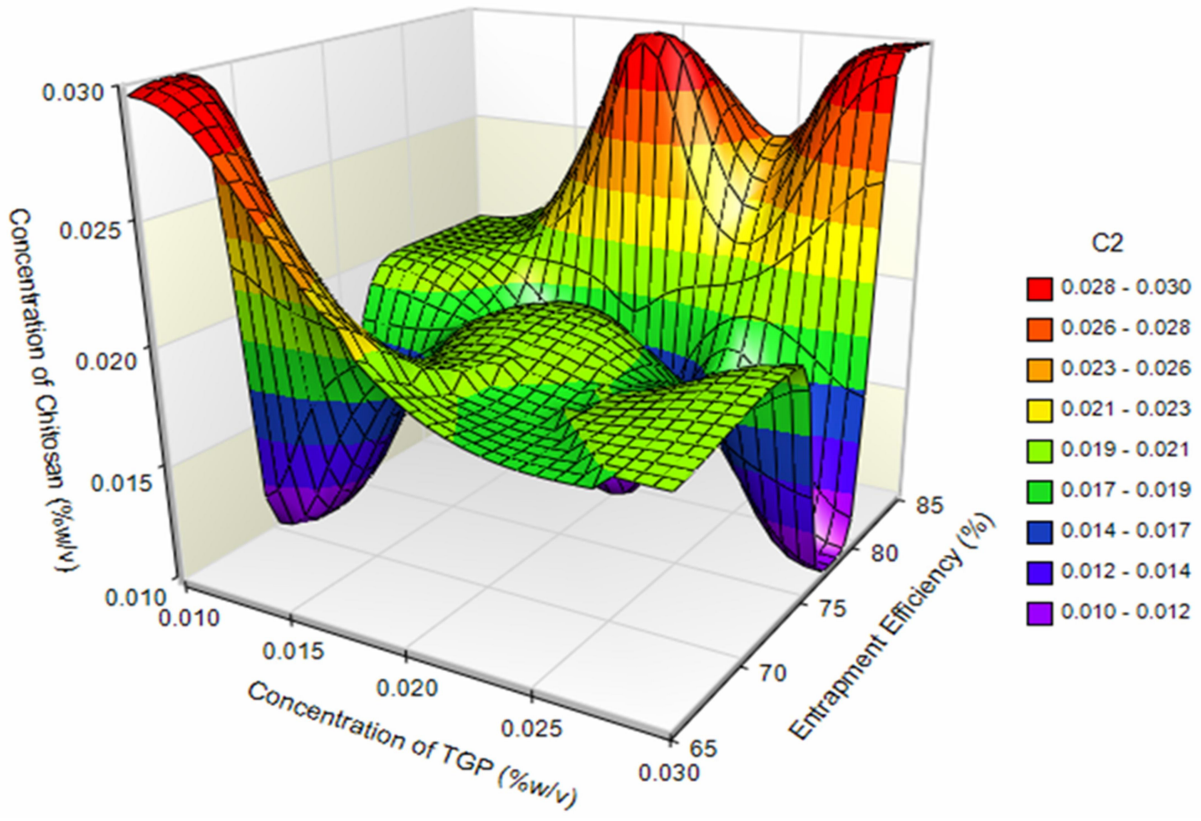

Figure 7 Surface plot for effect of independent variables over entrapment efficiency of nanoparticles.

the lowest zeta potential. Highest zeta potential was observed in the case of formulation T6. The entrapment efficiency of all formulations was found to be greater than $70 \%$ except in batch T1. Formulation T1 shows the highest entrapment efficiency, $83.36 \%$, shown in Table 6. Batch T1 consists of TGP and $\mathrm{Ch}$ in the highest concentration (Table 1).

The research study suggests that the dispersed nanosuspensions are generally evaluated for their entrapment efficiency. This is because in dispersed nanosuspensions the nanoparticles are distributed in a solvent system and the drug loading capacity (equation 15) requires total weight of nanoparticles.

$$
\text { Loading capacity }(\%)=\frac{\text { Entrapped drug }}{\text { Nanoparticle weight }} \times 100
$$

Therefore, in this study the formulated nanoparticles were not separated out and were only evaluated for their entrapment efficiency $/ \%$ loading capacity.

Usually in dispersed nanosuspensions, the nanoparticles are distributed in a solvent system and they are not separated out. This research aspect is also supported by several other researchers. ${ }^{62-64}$

The SEM image of prepared nanoparticles is shown in Figure 8. The scanning electron microscopy of the nanoparticles reveals their crystal shape. The SEM images showed rough surfaces of Ch (Figure 8A) and TGP (Figure 8B). Particles were also observed in the SEM images of TGP
(Figure 8B). Drug precipitates were found to be crystalline deposits (Figure 8C), while nanoformulation (T5) was found to be cubic in shape (Figure 8D). Operational voltage $(15 \mathrm{kV})$ was applied for SEM images of TGP (X15,000) and $\mathrm{Ch}(\mathrm{X} 15,000)$ and $30 \mathrm{kV}$ for the SEM images of drug precipitates (X10,000) and nanoparticles (T5) (X27,000).

Karfa et al made comparisons between spherical-shaped and cube-shaped nanoparticles of $\mathrm{Ag} / \mathrm{AgCl}$. In their investigation, it was observed that cube-shaped nanoparticles showed higher adsorption capacity to the receptor as compared to spherical nanoparticles. This ability may occur due to the high surface area of a nanocube in comparison to a spherical nanoparticle. ${ }^{65}$ According to a study conducted by Zhao et al, cube-shaped nanoparticles are more stable than spherical nanoparticles. ${ }^{66}$ Another study, by Kolhatkar et al, found that cubic-shaped nanoparticles provide better therapeutic effects on binding that spherical nanoparticles. ${ }^{67}$ So, in the present investigation, cube-shaped nanoparticles were prepared as the drug delivery carrier.

Figure 9 shows drug release of formulation through the egg membrane while Figure 10 shows drug release of formulation through the tomato membrane. The release study was carried out for $24 \mathrm{~h}$. It was observed that the release study through the egg membrane and the tomato membrane did not significantly alter the pattern of drug release. An initial burst release of the drug was observed at $15 \mathrm{~min}$ and $90 \mathrm{~min}$ followed by sustained release of the drug for 
Table 6 Characterization Parameters of PEC Stabilized Nanoparticles

\begin{tabular}{|l|c|c|c|c|c|}
\hline \multirow{2}{*}{ Formulation } & \multicolumn{5}{|c|}{ Characterization Parameters } \\
\cline { 2 - 6 } & Physical Appearance & $\mathbf{p H}$ & Particle Size (nm) & Zeta Potential (mV) & Entrapment Efficiency (\%) \\
\hline T1 & Clear solution & $4.1 \pm 0.01$ & 383.1 & 32.2 & $83.36 \pm 0.23$ \\
T2 & Clear solution & $4.3 \pm 0.00$ & 285.1 & 33.1 & $77.84 \pm 0.46$ \\
T3 & Clear solution & $4.3 \pm 0.01$ & 306.0 & 32.6 & $73.22 \pm 0.32$ \\
T4 & Clear solution & $4.1 \pm 0.01$ & 148.0 & 33.5 & $67.19 \pm 0.42$ \\
T5 & Clear solution & $4.1 \pm 0.01$ & 53.3 & 33.4 & $71.01 \pm 0.36$ \\
T6 & Clear solution & $4.2 \pm 0.00$ & 180.2 & 34.3 & $80.67 \pm 0.29$ \\
T7 & Clear solution & $4.2 \pm 0.01$ & 103.3 & 35.2 & $82.29 \pm 0.23$ \\
T8 & Clear solution & $4.2 \pm 0.01$ & 89.1 & 34.9 & $79.83 \pm 0.48$ \\
T9 & Clear solution & $4.2 \pm 0.01$ & 73.3 & 33.6 & $75.54 \pm 0.46$ \\
\hline
\end{tabular}

$24 \mathrm{~h}$. The retarded drug release was observed when the tomato membrane was used as a biological membrane in place of the egg membrane. Instead of retarded drug release through the tomato membrane, the basic release pattern remained the same as drug release through the egg membrane. Generally, a dialysis membrane is used as a biological barrier to investigate drug release characteristics. In the present investigation, a preliminary attempt was made to identify an alternative membrane for a drug release study. In future, further research will be needed into pore size, membrane stability, etc., in order to develop a new membrane. A correlation between synthetic and proposed natural membranes will need to be developed. Investigators believe this first-time exploratory study into tomato membranes as a novel and alternative natural biological barrier will inform other drug release studies. In future, this membrane can be a novel biological model that canopen up avenues for further research.

Times of $50 \%$ drug release $\left(\mathrm{T}_{50 \%}\right)$ and $80 \%$ drug release $\left(\mathrm{T}_{80 \%}\right)$ are tabulated in Table 7 .
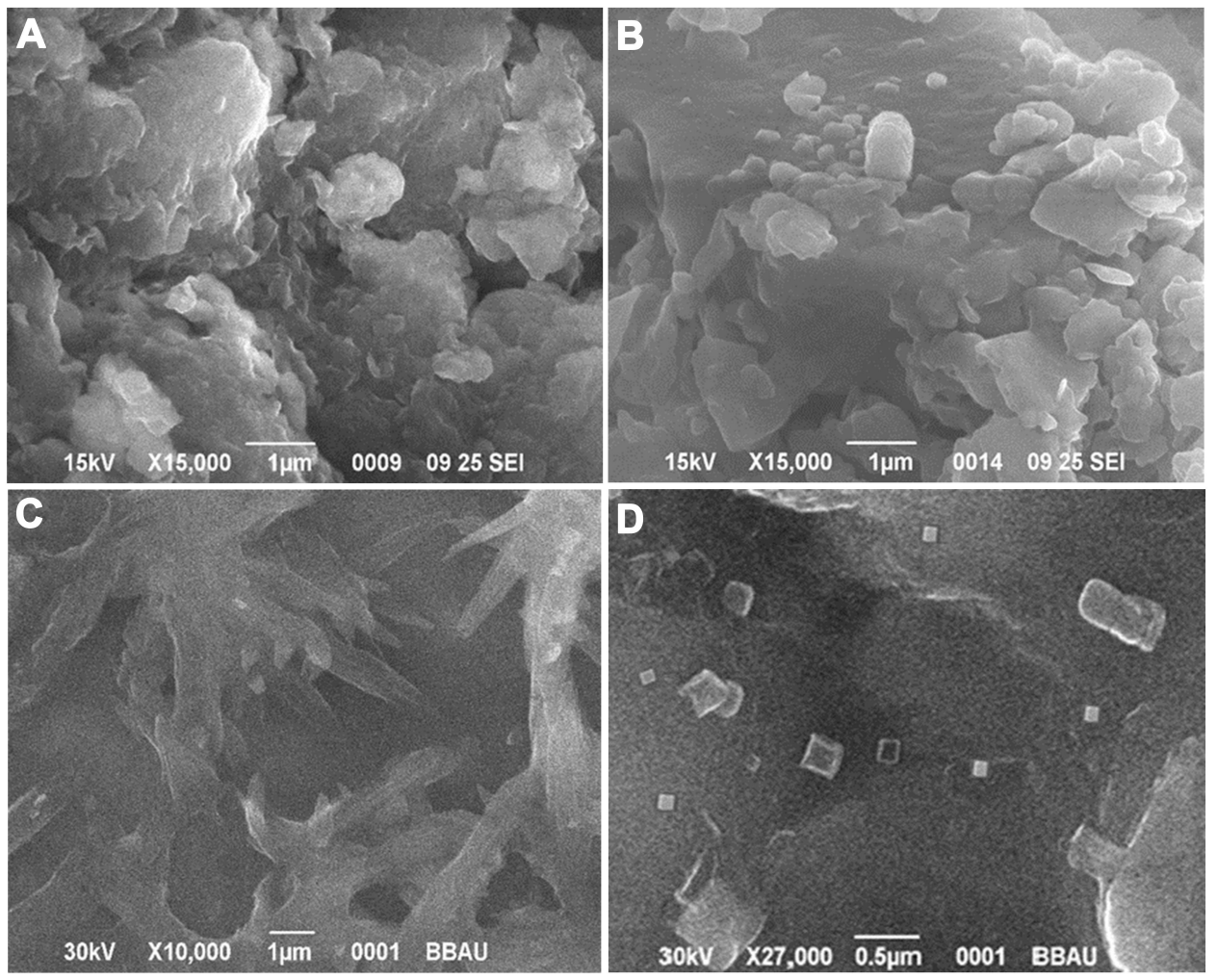

Figure 8 SEM image of (A) Ch, (B) TGP, (C) drug precipitates and (D) nanoparticles-T5. 

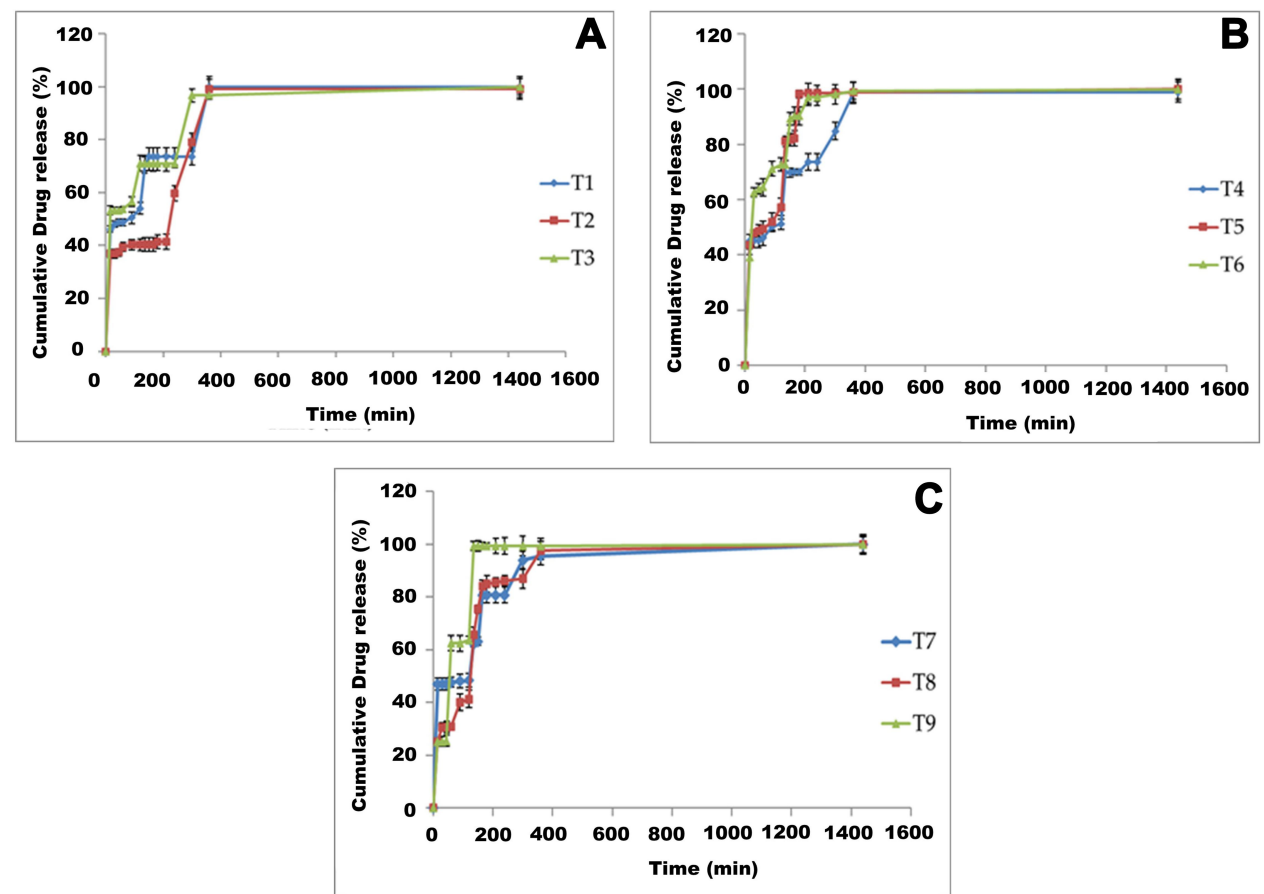

Figure 9 DR (\%) of formulations via egg membrane (A) TI, T2, T3; (B) T4, T5, T6; and (C) T7, T8, T9.

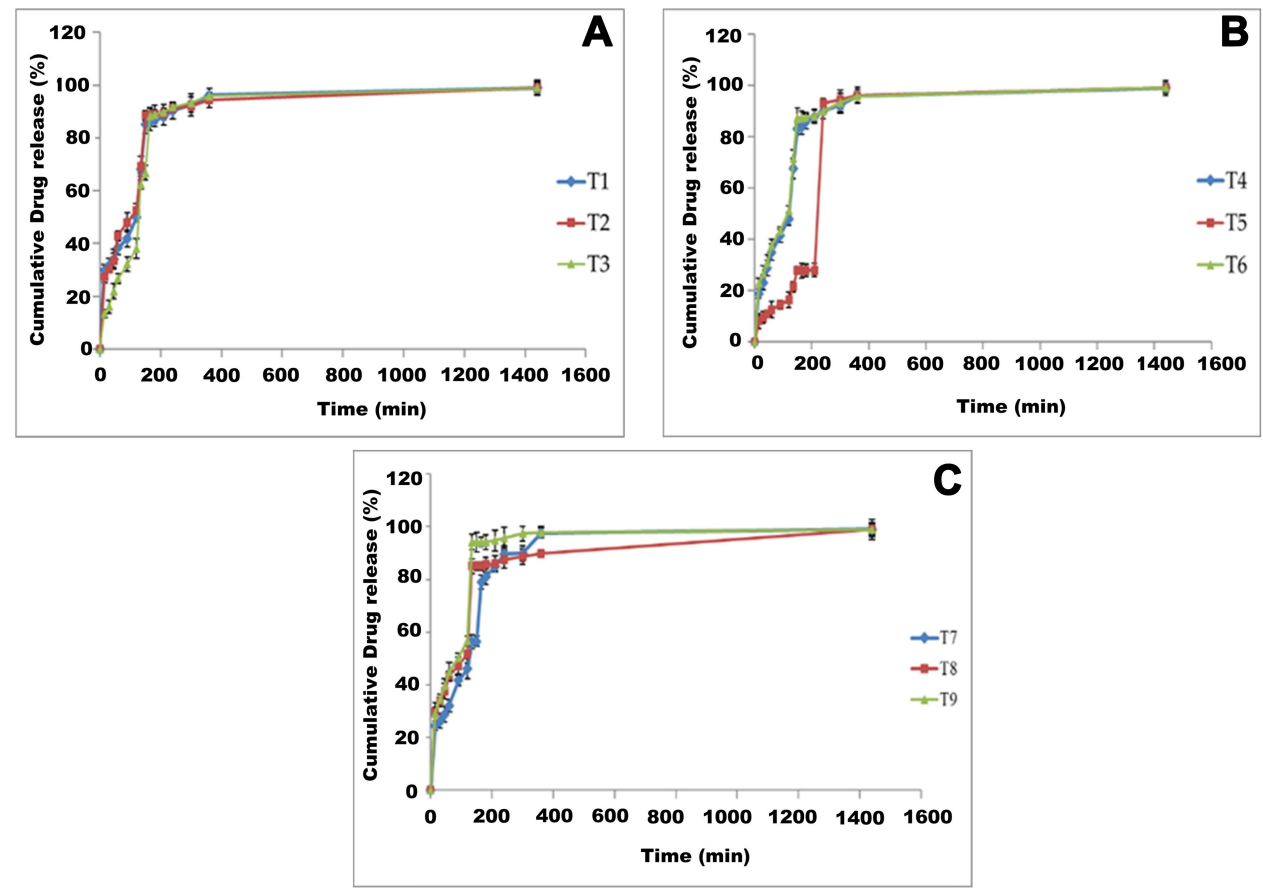

Figure 10 DR (\%) of formulations via tomato membrane (A) TI, T2, T3; (B) T4, T5, T6; and (C) T7, T8, T9.

From the kinetic study data (Tables 8 and 9), it was observed that the Baker-Lonsdale drug release model was followed by most of the formulations. After this model, the
Higuchi model was followed as the obtained $\mathrm{r}^{2}$ value was greater than all other models except the Baker-Lonsdale model. The Baker-Lonsdale model was derived from the 
Table $7 \mathrm{~T}_{50 \%}$ and $\mathrm{T}_{80 \%}$ of Prepared Nanoformulations

\begin{tabular}{|l|c|c|c|c|}
\hline \multirow{2}{*}{ Formulation } & \multicolumn{2}{|c|}{ Egg Membrane } & \multicolumn{2}{c|}{ Tomato Membrane } \\
\cline { 2 - 5 } & $\begin{array}{c}\mathbf{T}_{\mathbf{5 0}} \\
(\mathbf{m i n})\end{array}$ & $\begin{array}{c}\mathbf{T}_{\mathbf{8 0}} \\
(\mathbf{m i n})\end{array}$ & $\begin{array}{c}\mathbf{T}_{\mathbf{5 0}} \\
(\mathbf{m i n})\end{array}$ & $\begin{array}{c}\mathbf{T}_{\mathbf{8 0} \%} \\
\text { (min) }\end{array}$ \\
\hline T1 & 85 & 320 & 125 & 150 \\
T2 & 210 & 310 & 105 & 150 \\
T3 & 15 & 270 & 125 & 160 \\
T4 & 90 & 270 & 120 & 150 \\
T5 & 70 & 140 & 210 & 225 \\
T6 & 23 & 150 & 120 & 150 \\
T7 & 125 & 160 & 135 & 165 \\
T8 & 125 & 160 & 110 & 140 \\
T9 & 55 & 125 & 90 & 130 \\
\hline
\end{tabular}

Higuchi model. The Higuchi model was also used by other researchers investigatingr nanoparticles. ${ }^{68,69}$ The Higuchi model is based on three hypotheses. ${ }^{70}$ First, initial drug concentration in the matrix is much higher than drug solubility. Second, as particles are much smaller than system thickness, the drug particles are encapsulated inside the prepared nanoparticles and no drug is on the surface. Third, drug diffusivity is constant. The release occurs through pores in the matrix. This model follows the porous system, as hydrophilic polymer solubilizes easily and releases through pores. ${ }^{20}$

In the study, TGP was used as the polymer, which is hydrophilic and soluble when it comes in contact with the solvent system. Drug release through pores can be expressed by equation 16 .

$$
f_{1}=Q=\sqrt{\frac{D \delta}{\tau}}\left(2 C-\delta C_{s}\right) C_{s} t
$$

Data predicts that the Baker-Lonsdale model is followed by all formulations irrespective of the membrane

Table 8 Drug Release Data of PEC-based Nanoparticles Through Egg Membrane

\begin{tabular}{|c|c|c|c|c|c|c|c|c|c|c|c|c|c|}
\hline \multirow[t]{3}{*}{ Formulation } & \multicolumn{13}{|c|}{ Kinetics } \\
\hline & \multicolumn{2}{|c|}{$\begin{array}{l}\text { Zero Order } \\
\text { Kinetics }\end{array}$} & \multicolumn{2}{|c|}{$\begin{array}{l}\text { First Order } \\
\text { Kinetics }\end{array}$} & \multicolumn{2}{|c|}{$\begin{array}{l}\text { Higuchi } \\
\text { Kinetics }\end{array}$} & \multicolumn{2}{|c|}{$\begin{array}{l}\text { Baker Lonsdale } \\
\text { Kinetics }\end{array}$} & \multicolumn{2}{|c|}{$\begin{array}{l}\text { Hixson-Crowell } \\
\text { Kinetics }\end{array}$} & \multicolumn{3}{|c|}{$\begin{array}{c}\text { Kosermeyer Peppas } \\
\text { Kinetics }\end{array}$} \\
\hline & $\mathbf{R}^{2}$ & $\mathbf{K}_{\mathrm{o}}$ & $\mathbf{R}^{2}$ & $\mathbf{K}_{\mathrm{o}}$ & $\mathbf{R}^{2}$ & $\mathbf{K}_{\mathrm{o}}$ & $\mathbf{R}^{2}$ & $\mathbf{K}_{\mathrm{o}}$ & $\mathbf{R}^{2}$ & $\mathbf{K}_{\mathrm{o}}$ & $\mathbf{R}^{2}$ & $\mathbf{K}_{\mathrm{o}}$ & $\mathbf{R}^{2}$ \\
\hline TI & 0.389 & 0.043 & 0.103 & 0.0009 & 0.692 & 2.178 & 0.916 & 0.115 & 0.639 & 0.002 & 0.063 & 1.815 & 0.090 \\
\hline $\mathrm{T} 2$ & 0.5384 & 0.054 & 0.167 & 0.0011 & 0.726 & 1.482 & 0.895 & 0.092 & 0.642 & 0.003 & 0.010 & 2.207 & 0.095 \\
\hline T3 & 0.3537 & 0.041 & 0.091 & 0.0009 & 0.654 & 2.420 & 0.967 & 0.133 & 0.763 & 0.002 & 0.058 & 1.657 & 0.079 \\
\hline $\mathrm{T} 4$ & 0.3958 & 0.045 & 0.110 & 0.0011 & 0.707 & 2.096 & 0.907 & 0.112 & 0.642 & 0.003 & 0.073 & 1.893 & 0.073 \\
\hline T5 & 0.2541 & 0.043 & 0.094 & 0.0009 & 0.570 & 2.436 & 0.930 & 0.108 & 0.563 & 0.002 & 0.133 & 1.905 & 0.089 \\
\hline T6 & 0.2211 & 0.036 & 0.075 & 0.0011 & 0.540 & 2.930 & 0.965 & 0.112 & 0.559 & 0.002 & 0.153 & 1.676 & 0.123 \\
\hline T7 & 0.3614 & 0.045 & 0.108 & 0.0011 & 0.667 & 2.151 & 0.901 & 0.116 & 0.822 & 0.002 & 0.077 & 1.876 & 0.079 \\
\hline T8 & 0.3355 & 0.053 & 0.145 & 0.0011 & 0.646 & 1.716 & 0.925 & 0.060 & 0.783 & 0.003 & 0.129 & 2.795 & 0.067 \\
\hline T9 & 0.1942 & 0.045 & 0.108 & 0.0011 & 0.492 & 2.296 & 0.839 & 0.058 & 0.283 & 0.002 & 0.167 & 2.645 & 0.090 \\
\hline
\end{tabular}

Table 9 Drug Release Data of PEC Based Nanoparticles Through Tomato Membrane

\begin{tabular}{|c|c|c|c|c|c|c|c|c|c|c|c|c|c|}
\hline \multirow[t]{3}{*}{ Formulation } & \multicolumn{13}{|c|}{ Kinetics } \\
\hline & \multicolumn{2}{|c|}{$\begin{array}{c}\text { Zero-order } \\
\text { Kinetics }\end{array}$} & \multicolumn{2}{|c|}{$\begin{array}{l}\text { First-order } \\
\text { Kinetics }\end{array}$} & \multicolumn{2}{|c|}{$\begin{array}{l}\text { Higuchi } \\
\text { Kinetics }\end{array}$} & \multicolumn{2}{|c|}{$\begin{array}{l}\text { Baker Lonsdale } \\
\text { Kinetics }\end{array}$} & \multicolumn{2}{|c|}{$\begin{array}{l}\text { Hixson-Crowell } \\
\text { Kinetics }\end{array}$} & \multicolumn{3}{|c|}{$\begin{array}{c}\text { Kosermeyer Peppas } \\
\text { Kinetics }\end{array}$} \\
\hline & $\mathbf{R}^{2}$ & $\mathbf{K}_{\mathbf{o}}$ & $\mathbf{R}^{2}$ & $\mathbf{K}_{\mathbf{o}}$ & $\mathbf{R}^{2}$ & $\mathbf{K}_{\mathbf{o}}$ & $\mathbf{R}^{2}$ & $\mathbf{K}_{\mathbf{o}}$ & $\mathbf{R}^{2}$ & $\mathbf{K}_{\mathbf{o}}$ & $\mathbf{R}^{2}$ & $\mathbf{K}_{\mathbf{o}}$ & $\mathbf{R}^{2}$ \\
\hline TI & 0.300 & 0.049 & 0.082 & 0.0009 & 0.617 & 1.920 & 0.925 & $0.07 I$ & 0.656 & 0.003 & 0.103 & 1.637 & 1.638 \\
\hline T2 & 0.285 & 0.048 & 0.076 & 0.0009 & 0.605 & 1.978 & 0.946 & 0.066 & 0.640 & 0.002 & 0.123 & 1.606 & 1.606 \\
\hline T3 & 0.310 & 0.058 & 0.102 & 0.0011 & 0.616 & 1.489 & 0.750 & 0.028 & 0.625 & 0.003 & 0.145 & 2.067 & 2.068 \\
\hline T4 & 0.307 & 0.053 & 0.103 & 0.0009 & 0.625 & 1.719 & 0.927 & 0.044 & 0.663 & 0.003 & 0.133 & 1.989 & 1.990 \\
\hline T5 & 0.462 & 0.072 & 0.336 & 0.0018 & 0.639 & 1.139 & 0.522 & 0.011 & 0.673 & 0.003 & 0.402 & 5.869 & 5.869 \\
\hline T6 & 0.291 & 0.051 & 0.086 & 0.0009 & 0.609 & 1.848 & 0.934 & 0.055 & $0.64 I$ & 0.003 & 0.127 & 1.746 & 1.746 \\
\hline T7 & 0.359 & 0.054 & 0.084 & 0.0009 & 0.780 & 1.641 & 0.928 & 0.057 & 0.696 & 0.003 & 0.088 & 1.808 & 1.808 \\
\hline T8 & 0.291 & 0.046 & 0.069 & 0.0009 & 0.608 & 2.054 & 0.953 & 0.073 & 0.695 & 0.002 & 0.084 & 1.482 & 1.482 \\
\hline T9 & 0.227 & 0.045 & 0.056 & 0.0006 & 0.536 & 2.244 & 0.953 & 0.072 & 0.470 & 0.002 & 0.164 & 1.407 & 1.408 \\
\hline
\end{tabular}


used in the study. The calculated similarity factor was found to be 16.82. This means that the membranes are dissimilar in their drug release as the value observed was less than 50. All formulations of nanoparticles were subjected to size analysis on the 7 th, 14 th and 21 st days. The particle sizes of formulations after the mentioned days did not significantly differ from particle sizes on day 1 (data given in Table 10). No crystal growth was observed as particle size analysis showed a single peak during the analysis.

The particle size of nanoparticles in each formulation was found to be somewhat similar to the size of particles on day 1 . This means that crystal growth had not yet started, so there was no increase in particle size. After the 14th and 21st days, the size of particles increases as compared to previous days due to crystal growth and accumulation. Potential differences on the surfaces of nanoparticles of formulations were analyzed on the 7th, 14th and 21 st days and no significant deviation from initial readings was observed. After 14 days of study, no significant differences ( $p<0.05)$ were observed in the particle size and zeta potential of nanoformulations. Entrapment efficiency and particle size data on the initial day and after 45 days are tabulated in Table 11. Data obtained from stability studies showed a slight increase in size (maybe due to crystal growth) and a decrease in entrapment efficiency of nanoparticles (maybe due to leaching) after 45 days.

Generally, statins (3-hydroxy-3-methylgutaryl CoA reductase inhibitors) are considered to provide curative effects in the treatment of cardiovascular diseases. Based on some of the preclinical studies, they are
Table I I Stability Study Parameters of Nanoformulations

\begin{tabular}{|l|c|c|c|c|}
\hline \multirow{2}{*}{ Formulation } & \multicolumn{2}{|c|}{ Particle Size (nm) } & \multicolumn{2}{c|}{$\begin{array}{c}\text { Entrapment Efficiency } \\
\text { (\%) }\end{array}$} \\
\cline { 2 - 5 } & $\begin{array}{c}\text { Initial } \\
\text { Day }\end{array}$ & $\begin{array}{c}\text { After 45 } \\
\text { Days }\end{array}$ & $\begin{array}{c}\text { Initial } \\
\text { Day }\end{array}$ & $\begin{array}{c}\text { After 45 } \\
\text { Days }\end{array}$ \\
\hline TI & 383 & 387 & $83.36 \pm 0.42$ & $66.89 \pm 0.14$ \\
T2 & 285 & 289 & $77.84 \pm 0.46$ & $77.02 \pm 0.29$ \\
T3 & 306 & 310 & $73.22 \pm 0.32$ & $73.18 \pm 0.42$ \\
T4 & 148 & 155 & $67.19 \pm 0.23$ & $82.99 \pm 0.26$ \\
T5 & 53 & 59 & $71.01 \pm 0.36$ & $70.16 \pm 0.19$ \\
T6 & 180 & 186 & $80.67 \pm 0.29$ & $79.21 \pm 0.46$ \\
T7 & 103 & 106 & $82.29 \pm 0.23$ & $81.89 \pm 0.37$ \\
T8 & 89 & 94 & $79.83 \pm 0.48$ & $79.12 \pm 0.25$ \\
T9 & 73 & 78 & $75.54 \pm 0.46$ & $74.67 \pm 0.38$ \\
\hline
\end{tabular}

gaining interest as anticancer agents too. ${ }^{71}$ The effects of statins on the growth of breast cancer cells were evaluated. Statins have pleiotropic effects as a result of which they are gaining interest as anticancer agents. ${ }^{72}$ Investigation of simvastatin was carried out on the propagation of human breast cancer cell line MCF-7. As well as a cholesterol-lowering effect, statins may be important the deterrence of human breast cancer. In MCF-7 cells, activity like caspase-3 and DNA fragmentation is enhanced by simvastatin by which MCF7 cell propagation is inhibited. For the purpose of cell propagation, formation of mevalonate (cholesterol precursor) is required, catalyzed by HMG-CoA reductase. ${ }^{73}$ Growth of malignant cells can be damaged or weakened by inhibiting the synthesis of mevalonate. Simvastatin is reported to act as an osteolysis inhibitor in a mouse used as a model for breast cancer. Specifically, statins increase the apoptosis and

Table 10 Particle Growth Analysis and Zeta Potential After 7th Day, I4th Day and 2 Ist Day

\begin{tabular}{|c|c|c|c|c|c|c|}
\hline \multirow[t]{2}{*}{ Formulation } & \multicolumn{3}{|c|}{ Particle Size Growth (nm) } & \multicolumn{3}{|c|}{ Potential Difference (mV) } \\
\hline & After 7 Days & After I4 Days & After 21 Days & After 7 Days & After I4 Days & After 2I Days \\
\hline TI & 383.2 & 383.4 & 384.9 & 32.3 & 32.4 & 33.3 \\
\hline $\mathrm{T} 2$ & 285.1 & 285.3 & 287.3 & 33.2 & 33.4 & 34.9 \\
\hline T3 & 306.0 & 306.1 & 307.0 & 32.7 & 32.9 & 34.1 \\
\hline T4 & 148.1 & 148.6 & 150.1 & 33.6 & 33.8 & 34.8 \\
\hline T5 & 53.4 & 53.7 & 55.1 & 33.5 & 33.8 & 34.6 \\
\hline T6 & 180.2 & 180.3 & 181.9 & 34.4 & 34.6 & 36.1 \\
\hline T7 & 103.5 & 103.6 & 105.8 & 35.2 & 35.5 & 36.8 \\
\hline T8 & 89.2 & 89.5 & 91.1 & 35.1 & 35.2 & 37.0 \\
\hline T9 & 73.4 & 73.7 & 74.9 & 33.6 & 35.7 & 35.2 \\
\hline
\end{tabular}


radiosensitivity in different breast cancer cell lines, prevent proliferation and invasion, and decrease tumors' metastatic dissemination. Clinical findings show that statins minimize the recurrence rates of breast cancer when administered postdiagnostically. ${ }^{74,75}$ Many in vitro and animal studies indicate that statin drugs inhibit the development of breast cancer. Little evidence in human subjects supports a protective impact of statins on incidence of breast cancer, but consistent evidence supports a protective effect on recurrence of the disease.

As per the data given in Figure 11, T5 exhibits significantly higher death of human breast cancer cells (MCF-7) than pure drug in the in vitro conditions. It may be due to the smaller size of prepared nanoformulations than the particle size of pure drug. Smaller size of nanoformulations leads to better dissolution hence their therapeutic potential. Phagocytes exhibit fewer tendencies for non-spherical nanoparticles as compared to spherical nanoparticles. Attachment of elongated nanoparticles with cells with their axis also reduces the chance of phagocytosis. In their study, Huang et al demonstrated that aspect ratio of nanoparticles has a significant effect on internalization, differentiation, proliferation, adhesion and migration when studied in human melanoma cells A375. ${ }^{76}$ Godin et al evaluated the effect of spherical and nonspherical nanoparticles in murine model of breast cancer. They predicted that non-spherical particles would exhibit higher concentration than spherical particles within the breast cancer cells. ${ }^{77}$ Table 12 summarizes

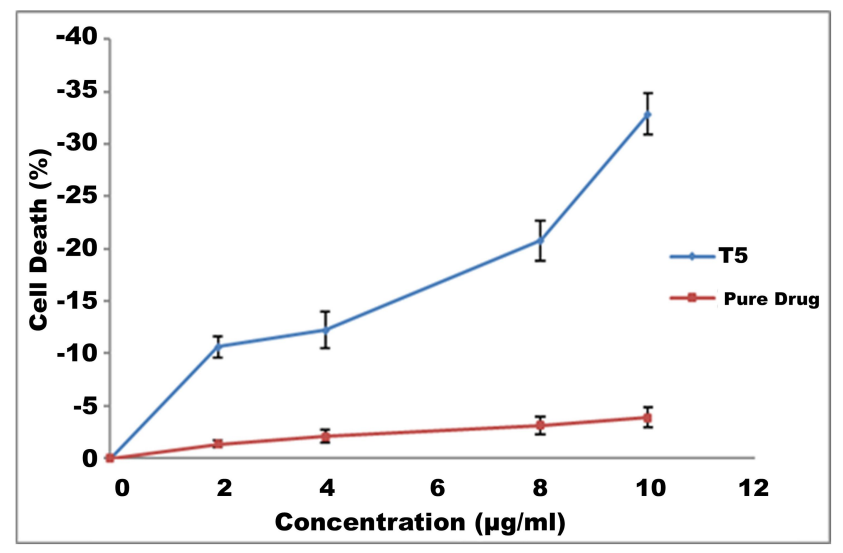

Figure II Anticancerous activity of nanoparticles (T5) and pure drug precipitates. the outcomes obtained from the chitosan-based PEC nanoparticles.

Figure 12 shows the bright field image of (a) untreated MCF-7 cells, (b) MCF-7 cells treated with T5, and (c) MCF-7 cells treated with pure simvastatin.

Table 13 describes cell death (\%) after the administration of pure drug and nanoparticles at different concentrations.

As discussed by Zhao et al, cytotoxicity of nanoparticles depends upon shape of the particles as well as types of cells used in the study. ${ }^{78}$ Hence, the present study specifically exhibited the results obtained on the human breast cancer cell lines. The opposite result was observed by $\mathrm{Li}$ et al, as they concluded that cellular uptake of spherical nanoparticles is higher than cube- and rod-shaped particles due to the ease of the bending capability of the cellular membrane around the nanoparticles. ${ }^{79}$ The observation of $\mathrm{Li}$ et al was also supported by Shimoni et al, as they showed that HeLa cell accumulation towards various nanoparticles depends upon the aspect ratio of particles. HeLa cells preferably accumulate towards the particles having a smaller aspect ratio. ${ }^{80}$

\section{Conclusion}

The present study was based on identification of the need to determine the effect of crystalline drug particles and cubic nanoparticles on human breast cancer cell lines (MCF-7). It can be concluded from the study that the antisolvent precipitation method allows control over the fabrication of cubic nanoparticles. This study also recommends that the present method can be easily adopted to control the shape, edge geometry and aspect ratio of nanoparticles. The study shows that solid cubic nanoparticles can be prepared using the solvent-antisolvent method and by utilizing Ch-TGP as a polyelectrolyte complex forming agent. Fabricated PEC-based nanoparticles exhibit good entrapment efficiency and ability to control drug release up to 24 h. Prepared cubic nanoparticles exhibited better control over the growth of human breast cancer cell lines (MCF-7) than pure drug precipitates in in vitro conditions. Simvastatin is an established hypolipidemic agent. Simvastatin has low aqueous solubility. In the present research, nanoparticles were prepared to increase the solubility of simvastatin. The literature also shows that simvastatin has some anticancer 
Table 12 List of Chitosan-based PEC Nanoparticles and Their Outcomes

\begin{tabular}{|c|c|}
\hline Chitosan-based PEC Nanoparticles & Outcome \\
\hline $\begin{array}{l}\text { Attallah et al prepared pectin/chitosan/jasmine oil nanoparticles (Pec/ } \\
\text { CS/JO NPs) by using Box-Behnken design (BBD). }{ }^{81}\end{array}$ & $\begin{array}{l}\text { The outcome was that pec/CS/JO NPs was effective against (MSF-7) } \\
\text { breast cancer cells, which was evaluated by using MTT assay, where it } \\
\text { was found that normal cells were not affected by the prepared } \\
\text { nanoparticle. }\end{array}$ \\
\hline $\begin{array}{l}\text { Guo et al formulated a chitosan-based nanogel to inhibit the } \\
\text { proliferation of breast cancer cell lines, where the model drug of 10- } \\
\text { hydroxycamptothecin (HCPT) was entrapped into core by facile } \\
\text { diffusion to form chitosan/I0-hydroxycamptothecin (CS/HCPT). }{ }^{82}\end{array}$ & $\begin{array}{l}\text { From the prepared formulation the outcome was evaluated by } \\
\text { assessing particle size, drug loading content and drug loading } \\
\text { efficiency. Further cytotoxicity, apoptosis of CS/HCPT, was also } \\
\text { investigated in vitro. }{ }^{82}\end{array}$ \\
\hline $\begin{array}{l}\text { Nascimento et al synthesized a delivery system in which non- } \\
\text { targeted delivery was done of chitosan, polyethylene glycol and } \\
\text { siRNA. }{ }^{83}\end{array}$ & $\begin{array}{l}\text { The outcome showed that there was an inhibition in tumor tissues in } \\
\text { animal model and faster elimination. }{ }^{83}\end{array}$ \\
\hline $\begin{array}{l}\text { Nascimento et al did another study and synthesized another delivery } \\
\text { system for targeted delivery, which was done by chitosan, polyethylene } \\
\text { glycol, RGFR-targeting peptide and siRNA. }{ }^{84}\end{array}$ & $\begin{array}{l}\text { In this research combination therapy was used, where chitosan-based } \\
\text { nanoparticles were combined with cisplatin in cancer models and tumor } \\
\text { tissues. }^{84}\end{array}$ \\
\hline $\begin{array}{l}\text { Jain et al developed a chitosan nanoparticle which was coupled with } \\
\text { hyaluronic acid with the help of inotropic gelation method, where } \\
\text { 5-fluorouracil (5FU) was chosen as the drug and used for the colon } \\
\text { cancer treatment. }^{85}\end{array}$ & $\begin{array}{l}\text { In the outcome, HA was incorporated in the chitosan nanoparticles } \\
\text { drug delivery system due to an elevated level of HA receptors around } \\
\text { tumor tissues. So, in the result, nanoparticles can target colon tumors } \\
\text { via both EPR effect and binding of hyaluronic acid to HA receptors and } \\
\text { chitosan-based nanoparticles were already loaded with } 5 \text {-fluorouracil } \\
\text { drug. }{ }^{85}\end{array}$ \\
\hline $\begin{array}{l}\text { Zhang et al reported a design of } \mathrm{pH} \text {-mediated chitosan-based microgel } \\
\text { DDS for treatment of cancer, where chitosan powder was dissolved in } \\
\text { water and then it was reacted with Glycidyltrimethylammonium } \\
\text { chloride to form } \mathrm{N} \text {-[(2-hydroxy-3-trimethylammonium)propyl]chitosan } \\
\text { chloride (HTCC). Further nanoparticles of HTCC were fabricated by } \\
\text { ionotropic method. }\end{array}$ & $\begin{array}{l}\text { Methotrexate disodium was also loaded in HTCC and in the outcome } \\
\text { of this research, it was found that in cell experiments MTX-loaded } \\
\text { HTCC highest mortality rate of Hela cells and cancerous cells was } \\
\text { found as compared to the pure drug group and non-conjugated MTX- } \\
\text { chitosan nanoparticle group. }{ }^{86}\end{array}$ \\
\hline $\begin{array}{l}\text { Yang et al successfully formulated oxaliplatin and miRNA-205-5p loaded } \\
\text { polyethyleneimine (PEI)/hyaluronic acid (HA) mesoporous silica-based } \\
\text { nanoparticles (OXmi-HSMN). This formulation was made to improve } \\
\text { therapeutic efficacy in colon cancers. }{ }^{87}\end{array}$ & $\begin{array}{l}\text { In the research, when tumors were extracted from the mice and } \\
\text { processed for TUNEL assay, it can clearly be seen in the assay that } \\
\text { OXmi-HMSN encouraged apoptosis of tumor cells when compared to } \\
\text { any other group which is producing a superior anticancer effect. OXmi- } \\
\text { HMSN leads to inhibition of tumor growth which is greater than any } \\
\text { other group, either OXL or OXL-MSN. So, their study provides the dua } \\
\text { therapeutics for enhanced therapeutic efficacy in the treatment of colon } \\
\text { cancer. }\end{array}$ \\
\hline $\begin{array}{l}\text { Cui et al did research and formulated a T7-modified, magnetic PLGA } \\
\text { nanoparticulate system (MNP/T7-PLGA NPs) through the process of } \\
\text { single-emulsion solvent evaporation method, in which nanoparticles } \\
\text { which are magnetic hydrophobic (MNPs) were entrapped into PLGA } \\
\text { NPs. }\end{array}$ & $\begin{array}{l}\text { In the outcome of this research, when comparison was done } \\
\text { between other conventional magnetic nanoparticles and these } \\
\text { PLGA NPs, it was found that PLGA NPs are more beneficial due to } \\
\text { their capability of co-encapsulation of various drugs. The efficiency } \\
\text { of treatment was investigated both in vitro and in vivo. }{ }^{88}\end{array}$ \\
\hline
\end{tabular}



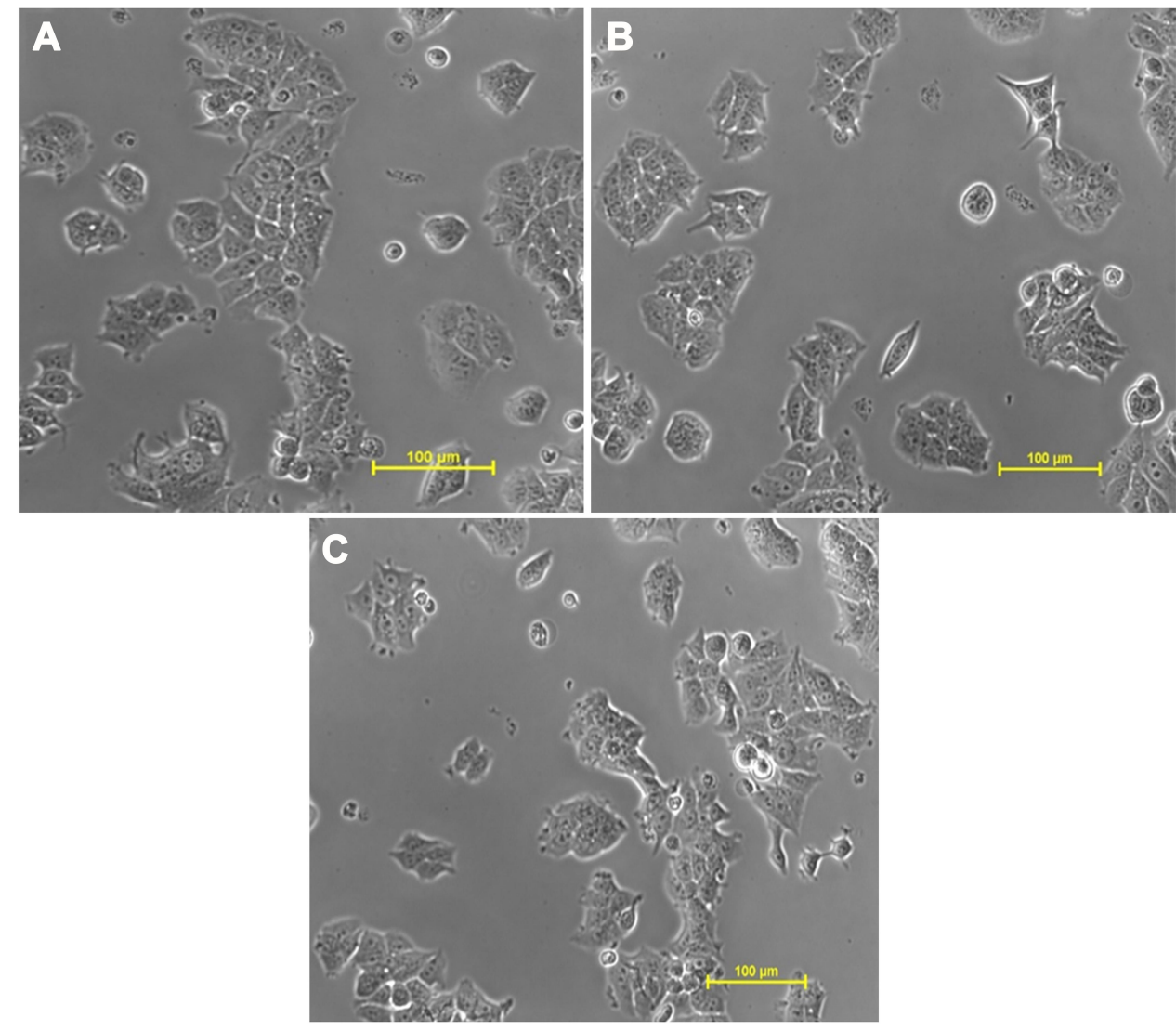

Figure I 2 Bright field image of (A) untreated MCF-7 cells, (B) MCF-7 cells treated with nanoparticles (T5) and (C) MCF-7 cells treated with pure simvastatin.

activity with hypolipidemic potential. Therefore, the present research provides an idea that use of simvastatin nanoparticles with an anticancer agent can be used for patients who have cancer and hyperlipidemic conditions. Simvastatin shows both hypolipidemic potential and a synergistic effect with an anticancer agent. The present study establishes that cubic nanoparticles of simvastatin have significantly better control over the growth of MCF-7 cells than pure simvastatin drug. In future, an in vivo animal model

Table 13 Cell Death (\%) After Administration of Pure Drug and Nanoparticles at Different Concentrations

\begin{tabular}{|l|c|c|}
\hline \multirow{2}{*}{ Concentration $(\mu \mathrm{g} / \mathrm{mL})$} & \multicolumn{2}{|c|}{ Cell Death (\%) } \\
\cline { 2 - 3 } & Pure Drug & Nanoparticle (T5) \\
\hline 0 & $0 \pm 0$ & $0 \pm 0$ \\
2 & $-10.61 \pm 0.37$ & $-1.36 \pm 0.96$ \\
4 & $-12.24 \pm 0.65$ & $-2.1 \pm 1.74$ \\
8 & $-20.75 \pm 0.84$ & $-3.12 \pm 1.87$ \\
10 & $-32.86 \pm 0.97$ & $-3.9 \pm 2.01$ \\
\hline
\end{tabular}

study will be required to identify the anticancer effects of the anti-hyperlipidemic agent simvastatin.

\section{Acknowledgments}

We gratefully appreciate the Galgotias University, India; AIMST University, Malaysia; MAHSA University, Malaysia; Tishk International University, Iraq; and the National University of Science and Technology, Sultanate Oman, Muscat, for their support in completing this study.

\section{Disclosure}

The authors report no conflicts of interest in this work.

\section{References}

1. U.S. Breast Cancer Statistics. Ardmore, PA: Breastcancer.org; 2021. Available from: https://www.breastcancer.org/symptoms/understand bc/statistics. Accessed December 1, 2020.

2. Aung TN, Qu Z, Kortschak RD, et al. Understanding the effectiveness of natural compound mixtures in cancer through their molecular mode of action. Int J Mol Sci. 2017;18:1-20. doi:10.3390/ ijms 18030656

3. Aravind SR, Joseph MM, Varghese S, et al. Antitumor and immunopotentiating activity of polysaccharide PST001 isolated from the seed kernel of Tamarindus indica: an in vivo study in mice. Sci World J. 2012;2012:1-14. doi:10.1100/2012/361382 
4. Walker JF. Simvastatin: the clinical profile. Am J Med. 1989;87:S44 S46. doi:10.1016/s0002-9343(89)80598-4

5. Wang ST, Ho HJ, Lin JT, et al. Simvastatin-induced cell cycle arrest through inhibition of STAT3/SKP2 axis and activation of AMPK to promote $\mathrm{p} 27$ and $\mathrm{p} 21$ accumulation in hepatocellular carcinoma cells. Cell Death Dis. 2017;8:e2626. doi:10.1038/cddis.2016.472

6. Hwang KE, Na KS, Park DS, et al. Apoptotic induction by simvastatin in human lung cancer A549 cells via Akt signaling dependent down-regulation of survivin. Invest New Drugs. 2011;29:945-952. doi:10.1007/s10637-010-9450-2

7. Joseph J, Kanchalochana SN, Rajalakshmi G, et al. Tamarind seed polysaccharide: a promising natural excipient for pharmaceuticals. Int J Green Pharm. 2012;6:270-278. doi:10.4103/0973-8258.108205

8. Shao H, Zhang H, Tian Y, et al. Composition and rheological properties of polysaccharide extracted from tamarind (Tamarindus indica L.) seed. Molecules. 2019;24:1-13. doi:10.3390/molecules24071218

9. Chawananorasest K, Saengtongdee P, Kaemchantuek P. Extraction and characterization of tamarind (Tamarind indica L.) seed polysaccharides (TSP) from three difference sources. Molecules. 2016; 21:1-9. doi:10.3390/molecules21060775

10. Singh R, Malviya R, Sharma PK. Extraction and characterization of tamarind seed polysaccharide as a pharmaceutical excipient Pharmacogn J. 2011;3:17-19. doi:10.5530/pj.2011.20.4

11. Katiyar N, Malviya R, Sharma PK. Pharmaceutical applications and formulation based patents of tamarindus indica seed polysaccharide and their modified derivatives. Adv Biol Res. 2014;8 (6):274-281.

12. Verma S, Bansal J, Kumar N, et al. Isolation and characterization studies of mucilage obtained from trigonella foenum greacum $l$. seed and Tamarindus indica polysaccharide as a pharmaceutical excipient. J Drug Deliv Ther. 2014;4(3):106-109.

13. Parhi R. Drug delivery applications of chitin and chitosan: a review. Environ Chem Lett. 2020;18:577-594. doi:10.1007/s10311-02000963-5

14. de Sousa Victor R, Marcelo da Cunha Santos A, Viana de Sousa B, de Araújo Neves G, Navarro de Lima Santana L, Rodrigues Menezes R. A review on Chitosan's uses as biomaterial: tissue engineering, drug delivery systems and cancer treatment. Materials. 2020;13:4995. doi:10.3390/ma13214995

15. Adhikari HS, Yadav PN. Anticancer activity of chitosan, chitosan derivatives, and their mechanism of action. Int $J$ Biomater. 2018;2018:1-29. doi:10.1155/2018/2952085

16. Wimardhani YS, Suniarti DF, Freisleben HJ, et al. Chitosan exerts anticancer activity through induction of apoptosis and cell cycle arrest in oral cancer cells. J Oral Sci. 2014;56:119-126. doi:10. 2334/josnusd.56.119

17. Savjani KT, Gajjar AK, Savjani JK. Drug solubility: importance and enhancement techniques. ISRN Pharm. 2012;2012:195727. doi:10. $5402 / 2012 / 195727$

18. Tambosi G, Coelho PF, Luciano S, et al. Challenges to improve the biopharmaceutical properties of poorly water-soluble drugs and the application of the solid dispersion technology. Matéria. 2018;23(4): e12224. doi:10.1590/s1517-707620180004.0558

19. Pucci C, Martinelli C, Ciofani G. Innovative approaches for cancer treatment: current perspectives and new challenges. E Cancer Med Sci. 2019;13:1-26.

20. Patra JK, Das G, Fraceto LF, et al. Nano based drug delivery systems: recent developments and future prospects. J Nanobiotechnology. 2018;16(1):71.

21. Lai WF, Shum HC. Hymermallose graft chitosan and its polyelectrolyte complex as novel systems for sustained drug delivery. ACS Appl Mater Interfaces. 2015;7:10501-10510. doi:10.1021/acsami. 5b01984

22. Lankalapalli S, Kolapalli VR. Polyelectrolyte complexes: a review of their applicability in drug delivery technology. Indian J Pharm Sci. 2009;71(5):481-487. doi:10.4103/0250-474X.58165
23. Akbari-Alavijeh S, Shaddel R, Jafari SM. Nanostructures of chitosan for encapsulation of food ingredients. In: Biopolymer Nanostructures for Food Encapsulation Purposes. Academic Press; 2019:381-418.

24. Rajabi H, Jafari SM, Rajabzadeh G, et al. Chitosan-gum Arabic complex nanocarriers for encapsulation of saffron bioactive components. Colloids Surf A. 2019;578:123644.

25. Patwekar SL, Potulwar AP, Pedewad SR, et al. Review on polyelectrolyte complex as novel approach for drug delivery system. Int J Pharm Pharm Res. 2016;5:98-109.

26. Potaś J, Szymańska E, Winnicka K. Challenges in developing of chitosan - based polyelectrolyte complexes as a platform for mucosal and skin drug delivery. Eur Polym J. 2020;140:110020. doi:10.1016/ j.eurpolymj.2020.110020

27. Dakhara SL, Anajwala C. Polyelectrolyte complex: a pharmaceutical review. Sys Rev Pharm. 2010;1:121-127. doi:10.4103/0975-8453. 75046

28. Mark HF, Bikales NM, Overberger CG, et al. Encyclopedia of Polymer Science. John Wiley and Sons, A Willey Interscience Publishers; 1987:739.

29. Jindal AB. The effect of particle shape on cellular interaction and drug delivery applications of micro- and nanoparticles. Int J Pharm. 2017;532:450-465. doi:10.1016/j.ijpharm.2017.09.028

30. Venkataramana K. Formulation characterization and in vitro, in vivo evaluation of stabilized rosuvastatin calcium nanosuspension. Int J Res Pharm Sci. 2020;11:2657-2664. doi:10.26452/ijrps.v11i2. 2280

31. Verma A, Nagarwal RC, Sharma SD, et al. Preparation and characterization of floating gellan-chitosan polyelectrolyte complex beads. Lat Am J Pharm. 2012;31:138-146.

32. Manchanda R, Arora SC, Manchanda R. Tamarind seed polysaccharide and its modifications-versatile pharmaceutical excipients-A review. Int J Pharm Technol Res. 2014;6:412-420.

33. Malviya R, Sharma PK, Dubey SK. Efficiency of self-assembled etoricoxib containing polyelectrolyte complex stabilized cubic nanoparticles against human cancer cells. Prec Med Sci. 2020;9:9-22. doi:10.1002/prm2.12004

34. Yousefpour P, Atyabi F, Dinarvand R, et al. Preparation and comparison of chitosan nanoparticles with different degrees of glutathione thiolation. DARU: J Fac Pharm Tehr Unv Med Sci. 2011;19: 367-375.

35. Cao D, Gong S, Shu X, et al. Preparation of $\mathrm{ZnO}$ nanoparticles with high dispersibility based on oriented attachment (OA) process. Nanoscale Res Lett. 2019;14:1-11. doi:10.1186/s11671-019-3038-3

36. Kumar A, Shinde J, Harinath N. Formulation, development and characterization of Simvastatin nanoparticles by solvent displacement method. Der Pharm Lett. 2014;6:145-155.

37. Why are DLS measurements in high concentration solutions difficult?. Holtsville, NY: Brookhaven Instruments Corporation; 2020. Available from: https://www.spectraresearch.com/wp-content /uploads/2019/08/DLS-High-Concentration.pdf. Accessed November $15,2020$.

38. Guide for Dynamic Light Scattering (DLS) sample preparation. Holtsville, NY: Brookhaven Instruments Corporation; 2020. Available from: https://www.brookhaveninstruments.com/guide-fordls-sample-preparation/. Accessed November 15, 2020.

39. Sondi I, Salopek-Sondi B. Silver nanoparticles as antimicrobial agent: a case study on E. coli as a model for Gram-negative bacteria. J Colloid Interface Sci. 2004;275:177-182. doi:10.1016/j. jcis.2004.02.012

40. Shid RL, Dhole SN, Kulkarni N, et al. Formulation and evaluation of nanosuspension delivery system for simvastatin. Int J Sci Nanotech. 2014;7:2459-2476.

41. Ong SGM, Ming LC, Lee KS, et al. Influence of the encapsulation efficiency and size of liposome on the oral bioavailability of griseofulvin-loaded liposomes. Pharmaceutics. 2016;8:1-17. doi:10.3390/pharmaceutics 8030025 
42. Modi S, Anderson BD. Determination of drug release kinetics from nanoparticles: overcoming pitfalls of the dynamic dialysis method. Mol Pharm. 2013;10:3076-3089. doi:10.1021/mp400154a

43. Malviya R. Green approach for fabrication of chitosan-neem gum polyelectrolyte stabilized penta and hexagonal nanoparticles and in-vitro cytotoxic potential toward breast cancer (MCF-7) cells. Prec Med Sci. 2020;9:68-82. doi:10.1002/prm2.12025

44. Weng J, Tong HH, Chow SF. In vitro release study of the polymeric drug nanoparticles: development and validation of a novel method. Pharmaceutics. 2020;12:1-18. doi:10.3390/pharmaceutics12080732

45. Costa P, Lobo JMS. Modeling and comparison of dissolution profiles. Eur J Pharm Sci. 2001;13:123-133. doi:10.1016/S0928-0987(01)00095-1

46. Simionato LD, Petrone L, Baldut M, et al. Comparison between the dissolution profiles of nine meloxicam tablet brands commercially available in Buenos Aires, Argentina. Saudi Pharm J. 2018;26:578-584. doi:10.1016/j.jsps.2018.01.015

47. Dash S, Murthy PN, Nath L, et al. Kinetic modeling on drug release from control drug delivery systems. Acta Pol Pharm. 2010;67:217-223.

48. Mircioiu C, Voicu V, Anuta V, et al. Mathematical modeling of release kinetics from supramolecular drug delivery systems. Pharmaceutics. 2019;11:1-45. doi:10.3390/pharmaceutics 11030140

49. Gohel MC, Sarvaiya KG, Shah AR, et al. Mathematical approach for the assessment of similarity factor using a new scheme for calculating weight. Indian J Pharm Sci. 2009;71:142-144. doi:10.4103/0250474X.54281

50. Muller M. Sizing, shaping and pharmaceutical applications of polyelectrolyte complex nanoparticles. In: Polyelectrolyte Complexes in the Dispersed and Solid State II. Berlin, Heidelberg: Springer; 2012:197-260.

51. Makoni PA, WaKasongo K, Walker RB. Short term stability testing of efavirenz-loaded solid lipid nanoparticle (SLN) and nanostructured lipid carrier (NLC) dispersions. Pharmaceutics. 2019;11:1-21. doi:10.3390/pharmaceutics 11080397

52. Rubin H. Deprivation of glutamine in cell culture reveals its potential for treating cancer. Proc Natl Acad Sci. 2019;116:6964-6968. doi:10.1073/pnas.1815968116

53. Rana K, Arora A, Bansal S, et al. Synthesis, in vitro anticancer and antimicrobial evaluation of novel substituted dihydropyrimidines. Indian J Pharm Sci. 2014;76:339-347.

54. Polexe RC, Delair T. Elaboration of stable and antibody functionalized positively charged colloids by polyelectrolyte complexation between chitosan and hyaluronic acid. Molecules. 2013;18:8563-8578. doi:10.3390/molecules 18078563

55. Kumar R, Siril PF, Javid F. Unusual anti-leukemia activity of nanoformulated naproxen and other non-steroidal anti-inflammatory drugs. Mater Sci Eng C. 2016;69:1335-1344. doi:10.1016/j. msec.2016.08.024

56. Jindal AB, Devarajan PV. Asymmetric lipid-polymer particles (LIPOMER) by modified nanoprecipitation: role of non-solvent composition. Int $J$ Pharm. 2015;489:246-251. doi:10.1016/j. ijpharm.2015.04.073

57. Oh WK, Kim S, Yoon H, et al. Shape-dependent cytotoxicity and proinflammatory response of poly(3,4-ethylenedioxythiophene) nanomaterials. Small. 2010;6:872-879. doi:10.1002/smll.200902074

58. Jansch M, Jindal AB, Sharmila BM, et al. Influence of particle shape on plasma protein adsorption and macrophage uptake. Pharmazie. 2013;68:27-33.

59. Caldorera-Moore M, Guimard N, Shi L, et al. Designer nanoparticles: incorporating size, shape, and triggered release into nanoscale drug carriers. Expert Opin Drug Deliv. 2010;7:479-495. doi:10.1517/ 17425240903579971

60. Akiyama Y, Mori T, Katayama Y, et al. Conversion of rod-shaped gold nanoparticles to spherical forms and their effect on biodistribution in tumor-bearing mice. Nanoscale Res Lett. 2012;7:565. doi:10.1186/1556-276X-7-565
61. Vacha R, Martinez-Veracoechea FJ, Frenkel D. Receptor-mediated endocytosis of nanoparticles of various shapes. Nano Lett. 2011;11:5391-5395. doi:10.1021/n12030213

62. Wang THY, Shen Y, Ao H, et al. Preparation of high drug-loading celastrol nanosuspensions and their anti-breast cancer activities in vitro and in vivo. Sci Rep. 2020;10:1-9. doi:10.1038/s41598019-56847-4

63. Ahuja M, Verma P, Bhatia M. Preparation and evaluation of chitosan-itraconazole co-precipitated nanosuspension for ocular delivery. $J \quad$ Exp Nanosci. 2015;10:209-221. doi:10.1080/17458080.20 13.822108

64. Dekate S, Bhairy S, Hirlekar R. Preparation and characterization of oral nanosuspension loaded with curcumin. Int J Pharm Pharm Sci. 2018;10:90-95. doi:10.22159/ijpps.20 18v10i6.22027

65. Karfa P, Madhuri R, Sharma PK. Is shape of $\mathrm{Ag} / \mathrm{AgCl}$ nanoparticle responsible for femtogram detection of alpha-feto protein: comparison between round and cube-shaped nanoparticle modified imprinted polymer. J Mater Chem B. 2016;4(33):5534-5547. doi:10.1039/ C6TB01306F

66. Zhao J, Baibuz E, Vernieres J, et al. Formation mechanism of Fe nanocubes by magnetron sputtering inert gas condensation. ACS Nano. 2016;10(4):4684-4694. doi:10.1021/acsnano.6b01024

67. Kolhatkar AG, Nekrashevich I, Litvinov D, Willson RC, Lee TR. Cubic silica-coated and amine-functionalized FeCo nanoparticles with high saturation magnetization. Chem Mater. 2013;25 (7):1092-1097. doi:10.1021/cm304111z

68. Tığlı Aydın RS, Pulat M. 5-Fluorouracil encapsulated chitosan nanoparticles for ph-stimulated drug delivery: evaluation of controlled release kinetics. J Nanomater. 2012;2012:1-10. doi:10.1155/2012/ 313961

69. Shoaib MH, Tazeen J, Merchant HA, et al. Evaluation of drug release kinetics from ibuprofen matrix tablets using HPMC. Pak J Pharm Sci. 2006;19:119-124.

70. Grassi M, Grassi G. Mathematical modelling and controlled drug delivery: matrix systems. Curr Drug Deliv. 2005;2:97-116. doi:10. 2174/1567201052772906

71. Chan KKW, Oza AM, Siu LL. The statins as anticancer agent. Clin Cancer Res. 2003;9:10-19.

72. Mandal CC, Ghosh-Choudhury N, Yoneda T, et al. Simvastatin prevents skeletal metastasis of breast cancer by an antagonistic interplay between p53 and CD44. J Biol Chem. 2011;286:11314-11327. doi:10.1074/jbc.M110.193714

73. Kotamraju S, Willams CL, Kalyanaraman B. Statin-induced breast cancer cell death: role of inducible nitric oxide and arginase-dependent pathways. Cancer Res. 2007;67:7386-7394. doi:10.1158/0008-5472.CAN-07-0993

74. Greenaway JB, Virtanen C, Osz K, et al. Ovarian tumour growth is characterized by mevalonate pathway gene signature in an orthotopic, syngeneic model of epithelial ovarian cancer. Oncotarget. 2016;7:47343-47365. doi:10.18632/oncotarget.10121

75. Duncan RE, Lau D, El-Sohemy A, et al. Geraniol and $\beta$-ionone inhibit proliferation, cell cycle progression, and cyclin-dependent kinase 2 activity in MCF-7 breast cancer cells independent of effects on HMG-CoA reductase activity. Biochem Pharmacol. 2004; 68:1739-1747. doi:10.1016/j.bcp.2004.06.022

76. Huang X, Teng X, Chen D, et al. The effect of the shape of Mesoporous silica nanoparticles on cellular uptake and cell function. Biomaterials. 2010;31:438-448. doi:10.1016/j.biomaterials. 2009.09.060

77. Godin B, Chiappini C, Srinivasan S, et al. Discoidal porous silicon particles: fabrication and biodistribution in breast cancer bearing mice. Adv Funct Mater. 2012;22:4225-4235. doi:10.1002/adfm.201200869

78. Zhao X, Ng S, Heng BC, et al. Cytotoxicity of hydroxyapatite nanoparticles is shape and cell dependent. Arch Toxicol. 2013;87:1037-1052. doi:10.1007/s00204-012-0827-1 
79. Li Y, Kroger M, Liu WK. Shape effect in cellular uptake of PEGylated nanoparticles: comparison between sphere, rod, cube and disk. Nanoscale. 2015;7:16631-16646. doi:10.1039/C5NR02 $970 \mathrm{H}$

80. Shimoni O, Yan Y, Wang Y, et al. Shape-dependent cellular processing of polyelectrolyte capsules. ACS Nano. 2013;7:522-530. doi:10.1021/nn3046117

81. Attallah OA, Shetta A, Elshishiny F, Mamdouh W. Essential oil loaded pectin/chitosan nanoparticles preparation and optimization via Boxâ "Behnken design against MCF-7 breast cancer cell lines. RSC Adv. 2020;10(15):8703-8708. doi:10.10 39/c9ra10204c

82. Guo H, Li F, Qiu H, et al. Chitosan-based nanogel enhances chemotherapeutic efficacy of 10-hydroxycamptothecin against human breast cancer cells. Int J Polym Sci. 2019;2019:1-6. doi:10.1155/ 2019/1914976

83. Nascimento AV, Gattacceca F, Singh A, et al. Biodistribution and pharmacokinetics of Mad2 siRNA-loaded EGFR-targeted chitosan nanoparticles in cisplatin sensitive and resistant lung cancer models. Nanomedicine. 2016;11:767-781. doi:10.2217/ nnm. 16.14
84. Nascimento AV, Singh A, Bousbaa H, Ferreira D, Sarmento B, Amiji MM. Overcoming cisplatin resistance in non-small cell lung cancer with Mad2 silencing siRNA delivered systemically using EGFR-targeted chitosan nanoparticles. Acta Biomater. 2017;47:71-80. doi:10.1016/j.actbio.2016.09.045

85. Jain A, Jain SK. In vitro and cell uptake studies for targeting of ligand anchored nanoparticles for colon tumors. Eur J Pharm Sci. 2008;35(5):404-416. doi:10.1016/j.ejps.2008.08.008

86. Zhang H, Mardyani S, Chan WCW, Kumacheva E. Design of biocompatible chitosan microgels for targeted $\mathrm{pH}$-mediated intracellular release of cancer therapeutics. Biomacromolecules. 2006;7 (5):1568-1572. doi:10.1021/bm050912z

87. Yang H, Liu Y, Qiu Y, Ding M, Zhang Y. MiRNA-204-5p and Oxaliplatin-loaded silica nanoparticles for enhanced tumor suppression effect in CD44-overexpressed colon adenocarcinoma. Int J Pharm. 2019;566:585-593. doi:10.1016/j.ijpharm.2019.06.020

88. Cui Y, Zhang M, Zeng F, Jin H, Xu Q, Huang Y. Dual-targeting magnetic PLGA nanoparticles for codelivery of paclitaxel and curcumin for brain tumor therapy. ACS Appl Mater Interfaces. 2016;8 (47):32159-32169. doi:10.1021/acsami.6b10175
International Journal of Nanomedicine

\section{Publish your work in this journal}

The International Journal of Nanomedicine is an international, peerreviewed journal focusing on the application of nanotechnology in diagnostics, therapeutics, and drug delivery systems throughout the biomedical field. This journal is indexed on PubMed Central, MedLine, CAS, SciSearch ${ }^{\circledR}$, Current Contents ${ }^{\circledR} /$ Clinical Medicine,
Dovepress

Journal Citation Reports/Science Edition, EMBase, Scopus and the Elsevier Bibliographic databases. The manuscript management system is completely online and includes a very quick and fair peer-review system, which is all easy to use. Visit http://www.dovepress.com/ testimonials.php to read real quotes from published authors. 